\title{
Integrative taxonomic approach to the cryptic diversity of Diplostomum spp. in lymnaeid snails from Europe with a focus on the 'Diplostomum mergi' species complex
}

\author{
Christian Selbach ${ }^{1 *}$, Miroslava Soldánová2, Simona Georgieva², Aneta Kostadinova² and Bernd Sures ${ }^{1,3}$
}

\begin{abstract}
Background: Recent molecular studies have discovered substantial unrecognised diversity within the genus Diplostomum in fish populations in Europe and North America including three species complexes. However, data from the first intermediate host populations are virtually lacking. This study addresses the application of an integrative taxonomic approach to the cryptic species diversity of Diplostomum spp. in natural lymnaeid snail populations in Europe with a focus on the 'D. mergi' species complex.

Methods: Totals of 1,909 Radix auricularia, 349 Radix peregra, 668 Stagnicola palustris and 245 Lymnaea stagnalis were sampled at five reservoirs of the Ruhr river system in Germany and screened for infections with Diplostomum spp. Cercariae were examined and identified alive, fixed and under scanning electron microscopy. Sequences from the barcode region of the cytochrome $c$ oxidase subunit 1 (cox1) mitochondrial gene and from the internal transcribed spacer cluster (ITS1-5.8S-ITS2) of the rRNA gene were amplified for 51 and 13 isolates, respectively.

Results: Detailed morphological and molecular analyses provided evidence for three named species (Diplostomum spathaceum, D. pseudospathaceum and D. parviventosum), and a further four species-level lineages ('D. mergi Lineages 2-4' and 'Diplostomum sp. Clade Q' in the lymnaeid snail populations from the Ruhr river basin. The paper provides the first descriptions of molecularly identified cercariae of $D$. spathaceum and of the cercariae of D. parviventosum, three lineages of the 'D. mergi' species complex and of 'Diplostomum sp. Clade Q'.

Conclusion: The integration of molecular and morphological evidence for Diplostomum spp. achieved in this study will serve as a baseline for species identification of these important parasites of snail and fish populations and thus advance further studies on the distribution of Diplostomum spp. in Europe.
\end{abstract}

Keywords: 'Diplostomum mergi' species complex, Diplostomum parviventosum, Diplostomum pseudospathaceum, Diplostomum spathaceum, Radix auricularia, Lymnaea stagnalis, Stagnicola palustris, Cercariae, cox1, ITS, Europe

\section{Background}

The incorporation of molecular data has brought a major advancement in species taxonomy, due to the possibility to distinguish cryptic species and re-evaluate existing morphological identification criteria. Especially for trematode species with complex life-cycles, where sampling often

\footnotetext{
* Correspondence: christian.selbach@uni-due.de

'Department of Aquatic Ecology and Centre for Water and Environmental Research (ZWU), University of Duisburg-Essen, Universitätsstraße 5, D-45141 Essen, Germany

Full list of author information is available at the end of the article
}

provides only one stage of a parasite's life-cycle at a time (e.g. cercariae or metacercariae only), molecular analyses provide an effective means of species identification and inference of complete life-cycles by matching data from the different life-cycle stages $[1,2]$. However, although larval trematodes in snails are potentially useful indicators of environmental conditions [3], they are difficult to identify and the taxonomic expertise is limited to few individuals [4]. This highlights the importance of providing accurate and accessible information on their identification.

\section{Ciomed Central}

(c) 2015 Selbach et al. This is an Open Access article distributed under the terms of the Creative Commons Attribution License (http://creativecommons.org/licenses/by/4.0), which permits unrestricted use, distribution, and reproduction in any medium, provided the original work is properly credited. The Creative Commons Public Domain Dedication waiver (http:// creativecommons.org/publicdomain/zero/1.0/) applies to the data made available in this article, unless otherwise stated. 
Diplostomum von Nordmann, 1832 is a major and important taxonomic group of widely distributed freshwater trematode parasites that utilise lymnaeid snails, fish and fish-eating birds to complete their life-cycles. Recent molecular studies have discovered higher than previously recognised diversity of Diplostomum spp. at small geographical scales. A total of 12 species was found in fishes in northern Canada based on molecular evidence: three named species, Diplostomum indistinctum (Guberlet, 1923), Diplostomum huronense (La Rue, 1927) and Diplostomum baeri Dubois, 1937, and a further nine unidentified species-level lineages of Diplostomum [5]. The first studies addressing integration of morphological assessment and molecular prospecting for species diversity of the genus in Europe resulted in molecular elucidation of the life-cycles of Diplostomum spathaceum (Rudolphi, 1819) (type-species) and D. pseudospathaceum Niewiadomska, 1984 and provided evidence for a substantial unrecognised genetic and morphological diversity, i.e. 15 species-level lineages including three complexes of genetically distinct lineages [6-9].

Six of these originate from the snail and fish populations studied in the River Ruhr drainage in Germany. Of particular importance is the finding of a number of isolates comprising three slightly divergent lineages within the 'D. mergi' species complex [6]. However, most of these isolates, i.e. ' $D$. mergi Lineage 3', originate from fish and due to the low sampling effort only few isolates from their lymnaeid snail hosts are available: a single isolate for ' $D$. mergi Lineage 1 ' and three isolates for ' $D$. mergi Lineage 2', all from Radix auricularia (L.).

The application of barcoding approach to species diversity of Diplostomum in Europe depends on the availability of sequence databases based on precisely identified isolates, a process that is currently impeded by the lack of taxonomic expertise (see Georgieva et al. [6] for detailed discussion). This highlights the need for combining molecular data with thorough morphological descriptions that will allow species delimitation and recognition in future studies. This study addresses the application of an integrative taxonomic approach to the cryptic species diversity of Diplostomum spp. in natural lymnaeid snail populations in Europe with a focus on the 'D. mergi' species complex. Detailed morphological and molecular data gathered in an extensive sampling of four lymnaeid species in five reservoirs of the Ruhr and its tributaries provided evidence for three named species and four distinct lineages of Diplostomum spp. The thorough morphological descriptions of the cercariae of $D$. parviventosum Dubois, 1932, D. pseudospathaceum, D. spathaceum and of the three novel lineages of the ' $D$. mergi' species complex and 'Diplostomum sp. Clade Q', in association with the molecular delineation provided here, will serve as a baseline for species identification of these important parasites of snail and fish populations and thus advance further studies on the distribution of Diplostomum spp. in Europe.

\section{Methods \\ Sample collection}

A total of 3,171 lymnaeid snails of four species [1,909 Radix auricularia (L.), 349 R. peregra (Müller), 668 Stagnicola palustris (Müller), 245 Lymnaea stagnalis (L.)] was collected and examined for trematode infections during the summer months (May to September) in 2012 and 2013. Snails were collected at several sampling sites in five reservoirs of the River Ruhr catchment area in North Rhine-Westphalia, Germany: Baldeneysee $\left(51^{\circ} 24^{\prime}\right.$ 20.08"N, 7²'22.47"E); Hengsteysee (51 ${ }^{\circ} 24^{\prime} 52.17^{\prime \prime} \mathrm{N}, 7^{\circ}$ $\left.27^{\prime} 42.55^{\prime \prime} \mathrm{E}\right)$; Hennetalsperre $\left(51^{\circ} 19^{\prime} 50.97^{\prime \prime} \mathrm{N}, 8^{\circ} 15^{\prime} 46.82^{\prime \prime} \mathrm{E}\right)$; Sorpetalsperre $\left(51^{\circ} 20^{\prime} 15.01^{\prime \prime} \mathrm{N}, 7^{\circ} 56^{\prime} 46.18^{\prime \prime} \mathrm{E}\right)$; and Versetalsperre $\left(51^{\circ} 10^{\prime} 55.71^{\prime \prime} \mathrm{N}, 7^{\circ} 40^{\prime} 57.12^{\prime \prime} \mathrm{E}\right.$ ) (see Fig. 1 and Table 1 for details). At each sampling site snails were collected randomly with hand-nets or picked by hand from sediment, stones and floating aquatic vegetation along the shore. In the laboratory all snails were measured, labelled and placed in separate beakers with lake water under a light source to stimulate cercarial emission. Snails that did not emit cercariae for several days were dissected and examined for the presence of prepatent infections. Prevalence was calculated for distinct samples (i.e. collected from one site within a locality on a given date) comprising more than 15 snails.

\section{Morphological data}

Cercariae were identified alive under light microscope and cercariae of Diplostomum spp. were identified based on the morphological descriptions and the key of Niewiadomska \& Kiselienè [10]. Detailed light microscopy photographs of cercariae of Diplostomum spp. were taken with an Olympus UC30 digital camera on an Olympus BX51 microscope and all visible (under light microscopy) features described by Niewiadomska \& Kiseliené [10] were recorded. Cercariae and/or sporocysts of all isolates were fixed in molecular grade ethanol for DNA isolation and sequencing and in cold and hot $4 \%$ formaldehyde solution for detailed analysis of the surface morphology and body spination by scanning electron microscopy (SEM) and for obtaining measurements from fixed materials. Formalin-fixed cercariae were post-fixed in $2 \%$ osmium tetroxide for two hours, washed in $0.1 \mathrm{M}$ phosphate buffer, dehydrated through an acetone series, point-dried and sputter-coated with gold for SEM. SEM photographs were taken with a JEOL JSM-7401 F field emission scanning electron microscope. Descriptions are based on examination of live and formalin-fixed material and digital photomicrographs from both light microscopy and SEM. Measurements were taken with the program 


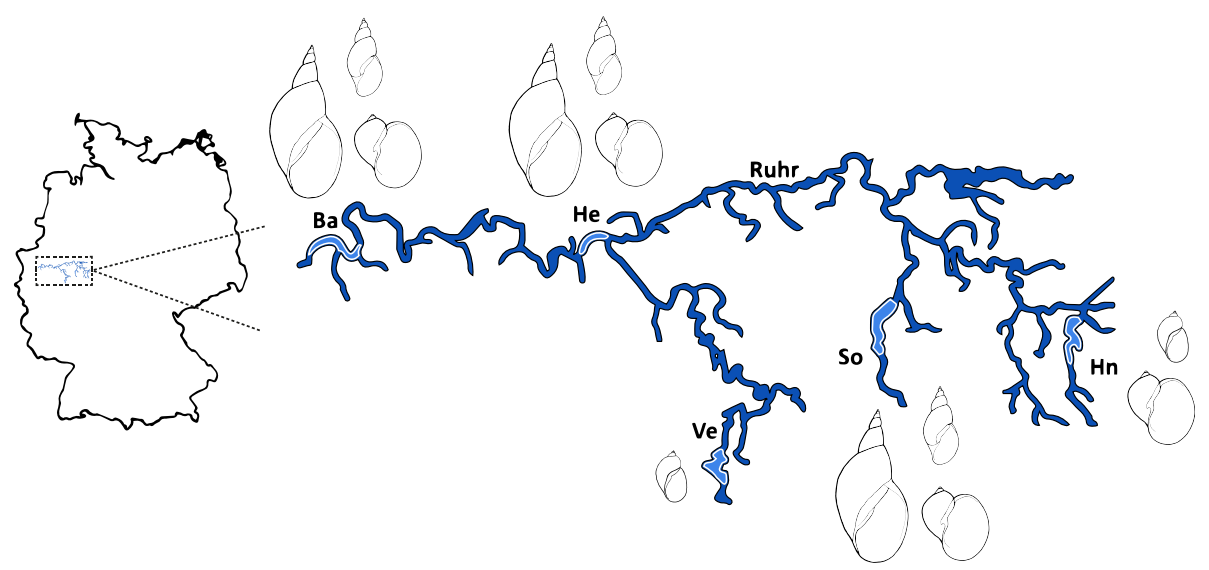

Fig. 1 Map of the Ruhr river system in Germany with sampling sites. Abbreviations: Ba, Baldeneyesee; He, Hengsteysee; Hn, Hennetalsperre; So, Sorpetalsperre; Ve, Versetalsperre. Lymnaea stagnalis; Radix auricularia; Radix peregra; Stagnicola palustris

Image $1.47 \mathrm{v}$ [11]; measurements in the descriptions are based on live specimens; measurements from fixed material are provided in the tables. All measurements in the text and tables are in micrometres and are presented as the range followed by the mean in parentheses. The following abbreviations for the metrical features were used: BL, body length; BW, maximum body width; AOL, anterior organ length; AOW, anterior organ width; VSL, ventral sucker length; VSW, ventral sucker width; TSL, tail stem length; TSW, tail stem width (at base); FL, furca length (see Additional file 1: Figure S1 for a schematic illustration of a cercaria showing the metrical features). The following relative proportions (ratios) were calculated for both live and fixed cercariae and used in addition to these measurements: VSW/AOW, ventral sucker width to anterior organ width ratio; BL/TSL, body length to tail stem length ratio; TSL/FL, tail stem length to furca length ratio.

\section{Molecular data}

Total genomic DNA was isolated from 100-200 ethanolfixed cercariae obtained from single snail individuals using the Chelex method (see [12] for details). Partial fragments of the barcode region of the cox 1 mitochondrial gene were amplified via polymerase chain reaction (PCR) using Ready-To-Go PCR beads (GE Healthcare, UK) and the PCR primers Plat-diploCOX1F (5'-CGT TTR AAT TAT ACG GAT CC-3') and Plat-diploCOX1R (5'-AGC ATA
GTA ATM GCA GCA GC-3') [13] as described in Georgieva et al. [6]. PCR amplifications of the ITS15.8S-ITS2 gene cluster were performed as above using the primers D1 (forward: 5'-AGG AAT TCC TGG TAA GTG CAA G-3') and D2 (reverse: 5'-CGT TAC TGA GGG AAT CCT GGT-3') [14].

PCR amplicons were purified using a QIAquick PCR purification kit (Qiagen Ltd, UK) and sequenced directly from both strands using the PCR primers (cox 1$)$ and the primers BD1 (forward: 5'-GTC GTA ACA AGG TTT CCG TA-3') and BD2 (reverse: $5^{\prime}$-TAT GCT TAA ATT CAG CGG GT-3') (ITS1-5.8S-ITS2; [14]) with ABI BigDye chemistry (ABI Perkin-Elmer, UK), alcohol-precipitated, and run on an ABI Prism 3130x1 automated sequencer. Contiguous sequences were assembled with MEGA v6 [15] and submitted to GenBank.

Sequences were aligned with Muscle implemented in MEGA v6. The 51 newly-generated cox 1 sequences were aligned with reference to the amino acid translation, using the echinoderm and flatworm mitochondrial code [16] together with 28 sequences retrieved from GenBank, the latter comprising $1-4$ representative sequences per species/lineage identified in previous studies in Europe [6, 17]; (see Additional file 2: Table S1 for details). The ITS1-5.8S-ITS2 sequences generated from selected isolates $(\mathrm{n}=13)$ from the cox 1 -derived clades were aligned with 32 published sequences, representative for the species/

Table 1 Summary data for the lymnaeid snails examined/infected with Diplostomum spp. in five reservoirs of the River Ruhr catchment area in Germany

\begin{tabular}{|c|c|c|c|c|c|c|}
\hline & $\mathrm{Ba}$ & $\mathrm{He}$ & So & $\mathrm{Hn}$ & Ve & Total \\
\hline Total number of lymnaeid snails examined & 437 & 1,772 & 357 & 292 & 313 & 3,171 \\
\hline Number of snails infected with Diplostomum spp. & 8 & 66 & 4 & - & - & 78 \\
\hline Number of distinct samples with Diplostomum spp. infections & $7(0)^{*}$ & $29(20)^{*}$ & $2(2)^{*}$ & - & - & $38(22)^{*}$ \\
\hline
\end{tabular}


lineages sequenced in Europe $[6,17,18]$ and Canada $[5,14]$. Sequences for Tylodelphys spp. were used as outgroups.

Distance-based neighbour-joining (NJ) and modelbased Bayesian inference (BI) algorithms were used for tree reconstruction. Prior to analyses the best-fit nucleotide substitution models were selected in jModelTest 2.1.1 [19, 20]. These were the Hasegawa-Kishino-Yano model including estimates of invariant sites and amongsite rate heterogeneity $(\mathrm{HKY}+\mathrm{I}+\mathrm{G})$ for the cox1 dataset and the Hasegawa-Kishino-Yano model including estimates of invariant sites $(\mathrm{HKY}+\mathrm{I})$ for the ITS dataset. BI analyses were carried out with MrBayes 3.2 [21] using Markov Chain Monte Carlo (MCMC) searches on two simultaneous runs of four chains during $10^{7}$ generations, sampling trees every $10^{3}$ generations. The first $25 \%$ of the sampled trees were discarded as with burn-in for each data set and the consensus tree topology and the nodal support were estimated from the remaining samples as posterior probability values [22]. Distance matrices (p-distance model, i.e. the percentage of pairwise character differences with pairwise deletion of gaps) were calculated with MEGA v6. The numbering scheme of Georgieva et al. [6] for the lineages of Diplostomum spp. was applied for consistency.

\section{Results}

\section{Overview of infections with Diplostomum spp.}

Examination of 3,171 lymnaeid snails belonging to four species revealed a total of 78 infections with Diplostomum spp. (overall prevalence of $2.5 \%$ ): 35 in Radix auricularia, 27 in Lymnaea stagnalis and 16 in Stagnicola palustris; no infections were found in Radix peregra. The majority of snails infected with Diplostomum spp. was collected in Hengsteysee, supporting the most abundant snail populations, whereas only few infected snails were found in Baldeneysee and Sorpetalsperre due to the lower snail density resulting in smaller sample size and none were recorded in either Hennetalsperre or Versetalsperre (Table 1). Prevalence of infections with Diplostomum spp. in distinct samples comprising more than 15 snails ranged from 1.0 to $16.7 \%$ (Table 2). The data in Table 2 also reveal the high diversity of Diplostomum spp. in Hengsteysee.

Using the key and descriptions in Niewiadomska \& Kiseliene [10] morphological identification of cercariae to the species level was achieved for two species, $D$. parviventosum ex $R$. auricularia and $D$. pseudospathaceum ex L. stagnalis. Subsamples of the remaining isolates were subjected to molecular identification based on sequence data [6, 17].

\section{Molecular analyses}

Partial cox 1 sequences were obtained for most of the isolates $(51 ; 65 \%)$ collected in Hengsteysee and Sorpetalsperre
Table 2 Prevalence of Diplostomum spp. in the distinct samples $(n \geq 15)$ of the three lymnaeid snail hosts examined

\begin{tabular}{|c|c|c|c|c|}
\hline Reservoir & Hengsteysee & & & Sorpetalsperre \\
\hline Snail species & R. auricularia & L. stagnalis & S. palustris & R. auricularia \\
\hline D. parviventosum & $3.1-7.1(2)$ & & & \\
\hline 'D. mergi Lineage 2' & $2.1-6.7(4)$ & & & $2.2-10.7(2)$ \\
\hline 'D. mergi Lineage 3' & $1.0-3.1(3)$ & & & \\
\hline D. mergi Lineage 4 & $1.0(1)$ & & & \\
\hline $\begin{array}{l}\text { 'Diplostomum sp. } \\
\text { Clade Q' }\end{array}$ & $3.6(1)$ & & & \\
\hline D. spathaceum & $2.1-4.1(4)$ & & & \\
\hline D. pseudospathaceum & & $3.7-16.7$ (6) & $1.0-8.7(5)$ & \\
\hline
\end{tabular}

Prevalence is calculated for sample size $n \geq 15$ only; the number of samples is given in parentheses

(see Table 3 for details). Both NJ and BI analyses of the cox1 dataset (410 nt) recovered eight reciprocally monophyletic lineages (Figs. 2, 3). The predominant part of the isolates ex $R$. auricularia $(\mathrm{n}=25 ; 76 \%)$ clustered with the isolates comprising ' $D$. mergi' species complex sensu Georgieva et al. [6] thus expanding substantially the content of the three lineages identified by these authors (Fig. 2). Nine isolates identified here as $D$. parviventosum based on morphology formed a strongly supported lineage ('D. mergi Lineage 1') together with the single isolate ex $R$. auricularia (JX986873) of Georgieva et al. [6], 11 further isolates clustered together with the three isolates ex $R$. auricularia (JX986874-JX986876) ('D. mergi Lineage 2' sensu Georgieva et al. [6]) and four isolates clustered with five metacercarial isolates ex Salmo trutta fario L. and Gobio gobio L. of the 'D. mergi Lineage 3' sensu Georgieva et al. [6]; this lineage was joined by a single isolate (RaHe20; further referred to as ' $D$. mergi Lineage 4'). The remaining isolates ex $R$. auricularia joined two additional strongly supported lineages: D. spathaceum (7 isolates) and 'Clade Q' sensu Georgieva et al. [6] (one isolate) represented by one cercarial isolate ex $R$. auricularia (RA97) and two metacercarial isolates ex $R$. rutilus (RR43 and RR45) from Lake Constance, all reported as D. spathaceum (see Behrmann-Godel [17]) but annotated as $D$. mergi in the GenBank. All isolates ex L. stagnalis and $S$. palustris were identified as and clustered with isolates of D. pseudospathaceum (Fig. 3).

The mean intraspecific divergence within the cox 1 dataset examined ranged between 0.30 and $0.95 \%$, i.e. below the range for mean divergence in the interspecific comparisons (4.3-14.7\%) (Table 4). The lowest value was obtained for the sister lineages 2 and 3 of the ' $D$. mergi' complex. The single isolate of $D$. mergi Lineage 4 exhibited lower divergence values in comparisons with isolates of Lineages 2 and 3 (3.7-3.9 and 2.4\%, respectively). A total of 13 ITS1-5.8S-ITS2 sequences (975 nt) was generated from isolates sub-sampled within the seven 
Table 3 Summary data for 51 isolates of Diplostomum spp. used for generation of the cox1 and ITS1-5.8S-ITS2 sequences

\begin{tabular}{|c|c|c|c|c|}
\hline Species & Isolate & Snail host & Reservoir & $\begin{array}{l}\text { GenBank accession number } \\
\text { (cox1/ITS1-5.8S-ITS2) }\end{array}$ \\
\hline D. parviventosum & RaHe1 & R. auricularia & Hengsteysee & KR149504 \\
\hline D. parviventosum & RaHe2 & R. auricularia & Hengsteysee & KR149505 \\
\hline D. parviventosum & RaHe3 & R. auricularia & Hengsteysee & KR149506 \\
\hline D. parviventosum & RaHe4 & R. auricularia & Hengsteysee & KR149507 \\
\hline D. parviventosum & RaHe5 & R. auricularia & Hengsteysee & KR149508 \\
\hline D. parviventosum & RaHe6 & R. auricularia & Hengsteysee & KR149509/KR149490 \\
\hline D. parviventosum & RaHe7 & R. auricularia & Hengsteysee & KR149510 \\
\hline D. parviventosum & RaHe8 & R. auricularia & Hengsteysee & KR149511/KR149491 \\
\hline D. parviventosum & RaHe9 & R. auricularia & Hengsteysee & KR149512/KR149492 \\
\hline 'D. mergi Lineage 2' & $\mathrm{RaBa} 1$ & R. auricularia & Baldeneysee & KR149513/KR149493 \\
\hline 'D. mergi Lineage 2' & RaHe10 & R. auricularia & Hengsteysee & KR149514 \\
\hline 'D. mergi Lineage 2' & RaHe11 & R. auricularia & Hengsteysee & KR149515 \\
\hline 'D. mergi Lineage 2' & RaHe12 & R. auricularia & Hengsteysee & KR149516 \\
\hline 'D. mergi Lineage 2' & RaHe13 & R. auricularia & Hengsteysee & KR149517 \\
\hline 'D. mergi Lineage 2' & RaHe14 & R. auricularia & Hengsteysee & KR149518 \\
\hline 'D. mergi Lineage 2' & RaHe15 & R. auricularia & Hengsteysee & KR149519/KR149494 \\
\hline 'D. mergi Lineage 2' & RaSo1 & R. auricularia & Sorpetalsperre & KR149520 \\
\hline 'D. mergi Lineage 2' & $\mathrm{RaSO} 2$ & R. auricularia & Sorpetalsperre & KR149521/KR149495 \\
\hline 'D. mergi Lineage 2' & RaSo3 & R. auricularia & Sorpetalsperre & KR149522 \\
\hline 'D. mergi Lineage 2' & RaSo4 & R. auricularia & Sorpetalsperre & KR149523 \\
\hline 'D. mergi Lineage 3' & RaHe16 & R. auricularia & Hengsteysee & KR149524/KR149496 \\
\hline 'D. mergi Lineage 3' & RaHe17 & R. auricularia & Hengsteysee & KR149525/KR149497 \\
\hline 'D. mergi Lineage 3' & RaHe18 & R. auricularia & Hengsteysee & KR149526/KR149498 \\
\hline 'D. mergi Lineage 3' & RaHe19 & R. auricularia & Hengsteysee & KR149527 \\
\hline D. mergi Lineage 4 & RaHe20 & R. auricularia & Hengsteysee & KR149528/KR149499 \\
\hline D. pseudospathaceum & LsBa1 & L. stagnalis & Baldeneysee & KR149529 \\
\hline D. pseudospathaceum & LsBa2 & L. stagnalis & Baldeneysee & KR149530 \\
\hline D. pseudospathaceum & LsHe1 & L. stagnalis & Hengsteysee & KR149531 \\
\hline D. pseudospathaceum & LsHe2 & L. stagnalis & Hengsteysee & KR149532/KR149500 \\
\hline D. pseudospathaceum & LsHe3 & L. stagnalis & Hengsteysee & KR149533/KR149501 \\
\hline D. pseudospathaceum & LsHe4 & L. stagnalis & Hengsteysee & KR149534 \\
\hline D. pseudospathaceum & LsHe5 & L. stagnalis & Hengsteysee & KR149535 \\
\hline D. pseudospathaceum & LsHe6 & L. stagnalis & Hengsteysee & KR149536 \\
\hline D. pseudospathaceum & SpBa1 & S. palustris & Baldeneysee & KR149537 \\
\hline D. pseudospathaceum & SpHe1 & S. palustris & Hengsteysee & KR149538 \\
\hline D. pseudospathaceum & SpHe2 & S. palustris & Hengsteysee & KR149539 \\
\hline D. pseudospathaceum & SpHe3 & S. palustris & Hengsteysee & KR149540 \\
\hline D. pseudospathaceum & SpHe4 & S. palustris & Hengsteysee & KR149541 \\
\hline D. pseudospathaceum & SpHe5 & S. palustris & Hengsteysee & KR149542 \\
\hline D. pseudospathaceum & SpHe6 & S. palustris & Hengsteysee & KR149543 \\
\hline D. pseudospathaceum & SpHe7 & S. palustris & Hengsteysee & KR149544 \\
\hline D. pseudospathaceum & SpHe8 & S. palustris & Hengsteysee & KR149545 \\
\hline D. pseudospathaceum & SpHe9 & S. palustris & Hengsteysee & KR149546 \\
\hline
\end{tabular}


Table 3 Summary data for 51 isolates of Diplostomum spp. used for generation of the cox 1 and ITS1-5.8S-ITS2 sequences (Continued)

\begin{tabular}{|c|c|c|c|c|}
\hline D. spathaceum & RaHe21 & R. auricularia & Hengsteysee & KR149547 \\
\hline D. spathaceum & RaHe22 & R. auricularia & Hengsteysee & KR149548 \\
\hline D. spathaceum & RaHe23 & R. auricularia & Hengsteysee & KR149549 \\
\hline D. spathaceum & RaHe24 & R. auricularia & Hengsteysee & KR149550 \\
\hline D. spathaceum & RaHe25 & R. auricularia & Hengsteysee & KR149551/KR149502 \\
\hline D. spathaceum & RaHe26 & R. auricularia & Hengsteysee & KR149552 \\
\hline D. spathaceum & RaHe27 & R. auricularia & Hengsteysee & KR149553 \\
\hline 'Diplostomum sp. Clade Q' & RaHe28 & R. auricularia & Hengsteysee & KR149554/KR149503 \\
\hline
\end{tabular}

cox1 lineages of newly-collected Diplostomum spp. The analysis of the ITS data supported the molecular identification of these isolates from $\operatorname{cox} 1$ gene trees except for $D$. mergi Lineage 4 which clustered within the isolates of ' $D$. mergi Lineage 2' (Fig. 4).
Detailed morphological assessment of the isolates following the identification of independent evolutionary lineages confirmed their distinct status. Using the new set of morphological characters defined for each lineage, all isolates were assigned to lineage. Taken together, the results

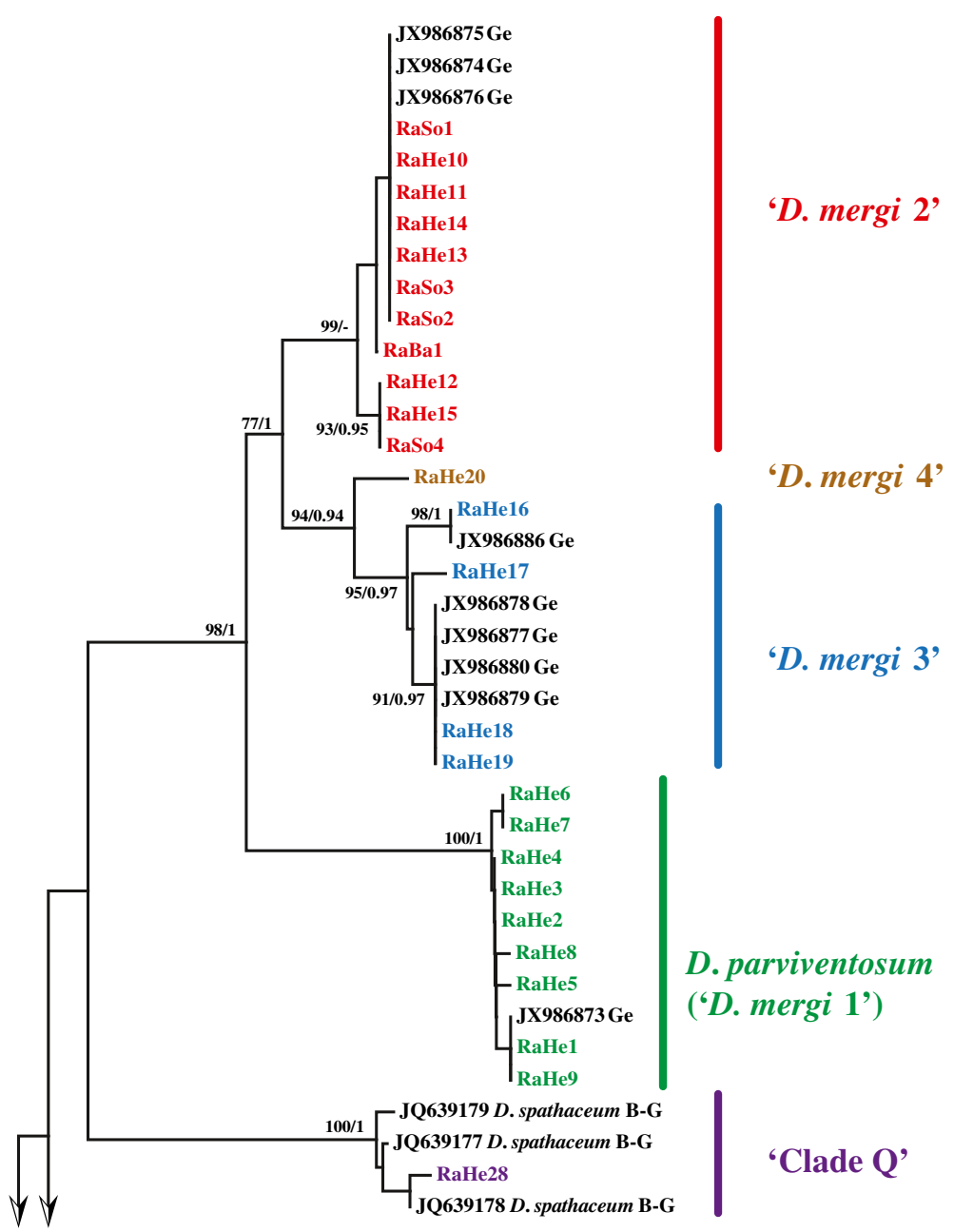

Fig. 2 Neighbour-joining (NJ) phylogram for Diplostomum spp. reconstructed using 51 newly-generated and 28 cox 1 sequences retrieved from GenBank. Nodal support from NJ and Bayesian Inference (BI) analyses indicated as NJ/BI. The scale bar indicates the expected number of substitutions per site. The newly-sequenced isolates are coded as in Table 3. Sequence identification is as in GenBank, followed by a letter: B-G, Behrmann-Godel [17]; Ge, Georgieva et al. [6] 


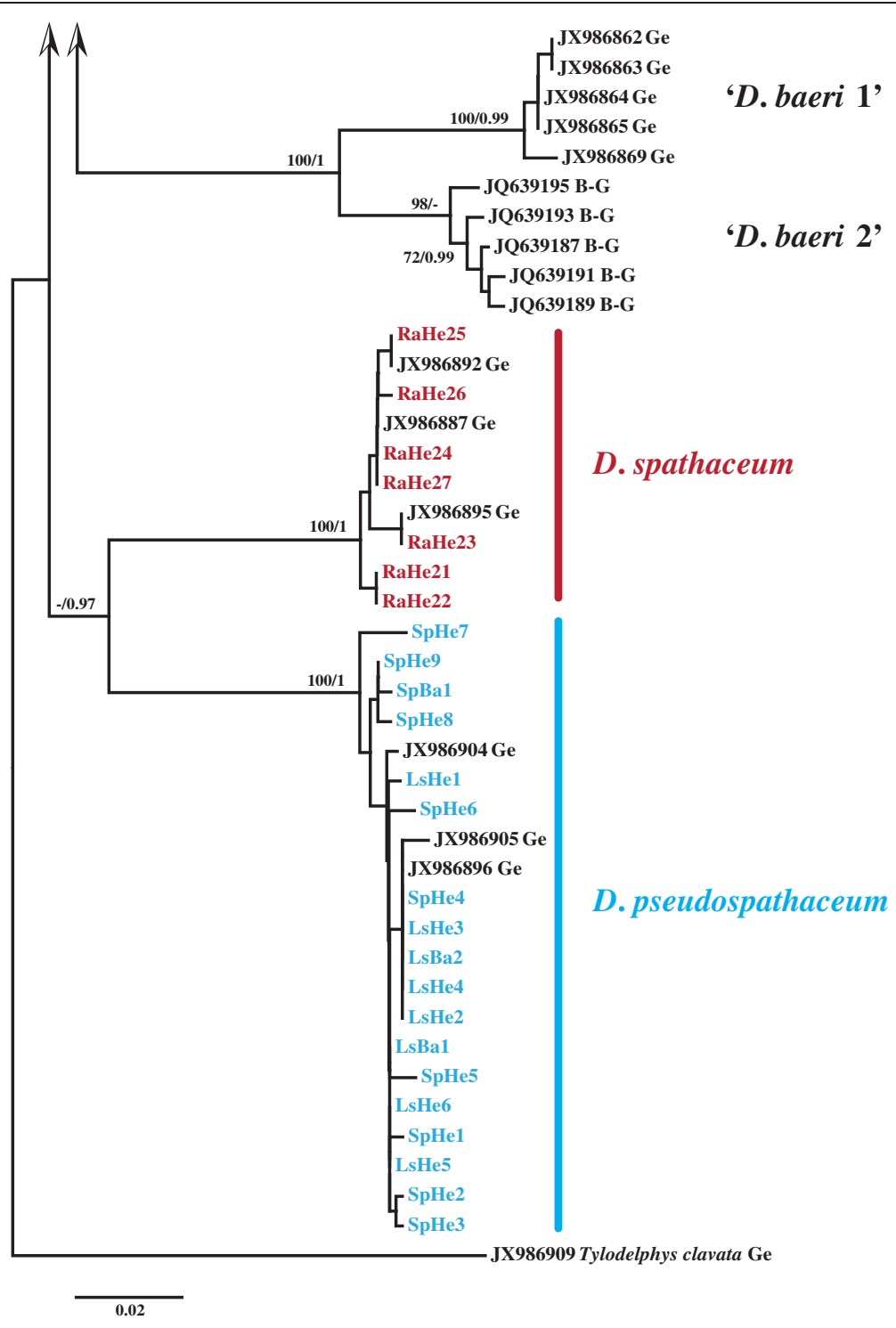

Fig. 3 Neighbour-joining (NJ) phylogram for Diplostomum spp. reconstructed using 51 newly-generated and 28 cox 1 sequences retrieved from GenBank; continuation of Fig. 2. Nodal support from NJ and Bayesian Inference (BI) analyses indicated as NJ/BI. The scale bar indicates the expected number of substitutions per site. Codes for the newly-sequenced isolates are provided in Table 3 . Sequence identification is as in GenBank, followed by a letter: B-G, Behrmann-Godel [17]; Ge, Georgieva et al. [6]

from the molecular and morphological analyses suggest that isolates sampled in lymnaeid snails from Germany represent three named species and four distinct lineages of Diplostomum spp. Descriptions of the cercariae of $D$. parviventosum, D. pseudospathaceum, D. spathaceum and of the three novel lineages of the ' $D$. mergi' species complex plus 'Diplostomum sp. Clade Q' are provided below.

Descriptions of the cercariae of Diplostomum spp. based on the molecular voucher material

Diplostomum parviventosum Dubois, 1932

First intermediate host: Radix auricularia (Linnaeus). Locality: Hengsteysee, Germany.
[Figure 5 and Additional file 3: Figure S2A, Additional file 4: Figure S3A, Additional file 5: Figure S4A. Measurements of formalin-fixed specimens are provided in Table 5.] Body elongate-oval, $127-164 \times 53-86(146 \times$ $62)$, shorter than tail stem $[\mathrm{BL} / \mathrm{TSL}=0.7-0.9(0.8)]$, with aggregations of yellow pigment in parenchyma on both sides of terminal organ and around ventral sucker (Fig. 5a, b). Anterior organ elongate-oval, with posterior margin reaching to mid-length of forebody, $42-67 \times 23$ $-40(51 \times 32)$. Ventral sucker spherical, small, somewhat post-equatorial, $31-44 \times 30-48(37 \times 37)$, with fine undulating membrane (3 high) (Fig. $5 \mathrm{~d}$ ); width slightly exceeds width of anterior organ $[\mathrm{VSW} / \mathrm{AOW}=1.1-1.3$ 
Table 4 Mean divergence (uncorrected p-distance in \%) estimated for the cox 1 sequence pairs within- (diagonal) and among species and lineages of Diplostomum

\begin{tabular}{lllllllll}
\hline & 1 & 2 & 3 & 4 & 5 & 6 & 7 \\
\hline 1 & 'Diplostomum sp. Clade Q' & 0.56 & & & & & \\
2 & D. baeri (trout) 1 & 13.5 & 0.44 & & & & \\
3 & D. baeri (perch) 2 & 13.3 & 6.5 & 0.95 & & & \\
4 & D. parviventosum* & 11.1 & 13.9 & 13.0 & 0.30 & & & \\
5 & 'D. mergi Lineage 2' & 10.9 & 13.8 & 13.8 & 6.7 & 0.30 & 0.65 & 0.65 \\
6 & 'D. mergi Lineage 3' & 11.0 & 14.4 & 14.7 & 6.9 & 4.3 & 12.9 & 10.0 \\
7 & D. pseudospathaceum & 12.0 & 14.7 & 13.2 & 13.9 & 12.0 & 0.53 \\
8 & D. spathaceum & 12.1 & 14.6 & 12.4 & 11.2 & 10.7 & 11.6 & 10.0
\end{tabular}

*'D. mergi Lineage 1' of Georgieva et al. [6]

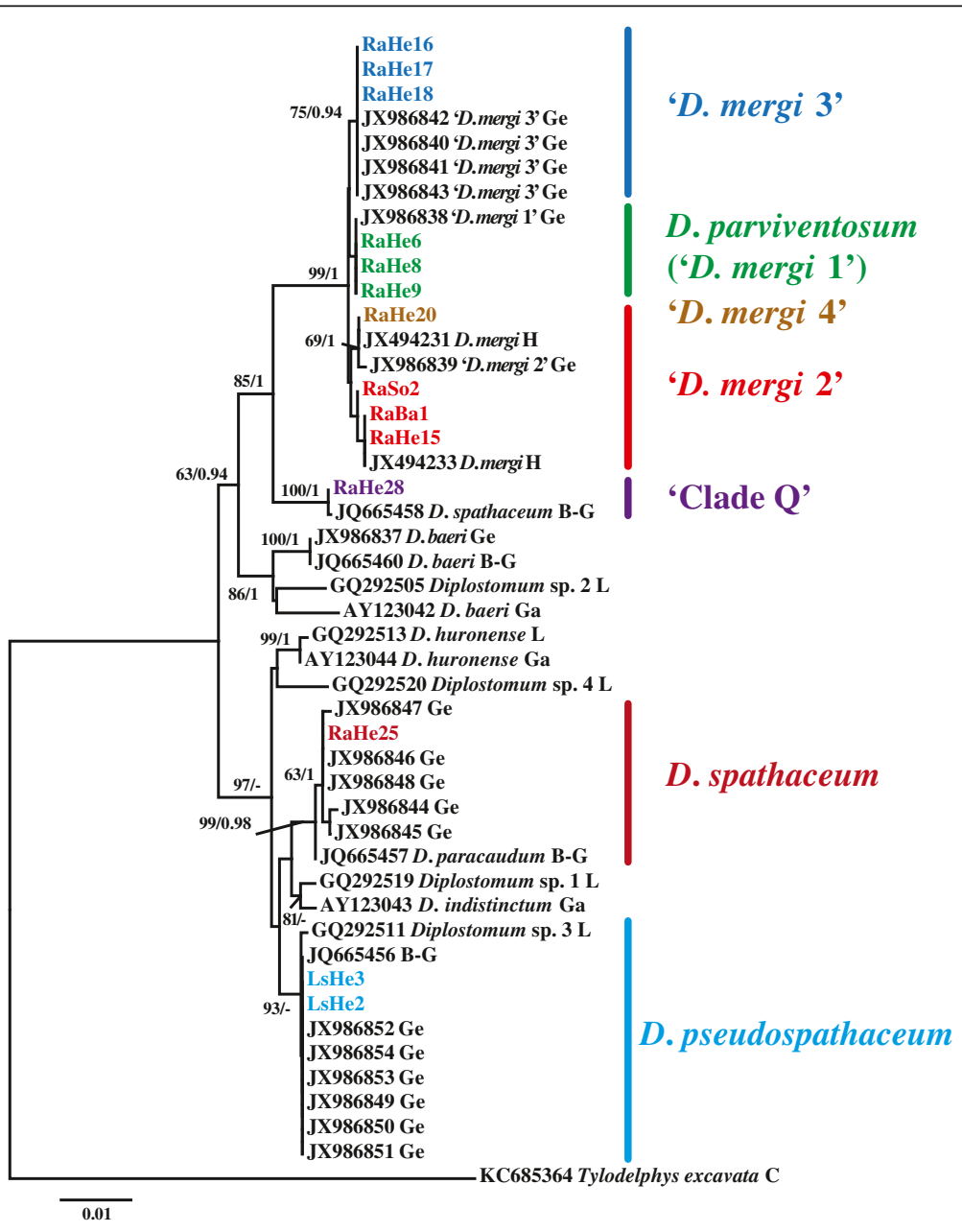

Fig. 4 Neighbour-joining (NJ) phylogram for Diplostomum spp. reconstructed using 13 newly-generated and 32 ITS1-5.8S-ITS2 sequences retrieved from GenBank. Outgroup: Tylodelphys excavata. Nodal support from NJ and Bayesian Inference (BI) analyses are indicated as NJ/Bl. The scale bar indicates the expected number of substitutions per site. Codes for the newly-sequenced isolates are provided in Table 3. Sequence identification is as in GenBank, followed by a letter: B-G, Behrmann-Godel [17]; Ge, Georgieva et al. [6]; Ga, Galazzo et al. [14]; H, Haarder et al. [18]; L, Locke et al. [5] 


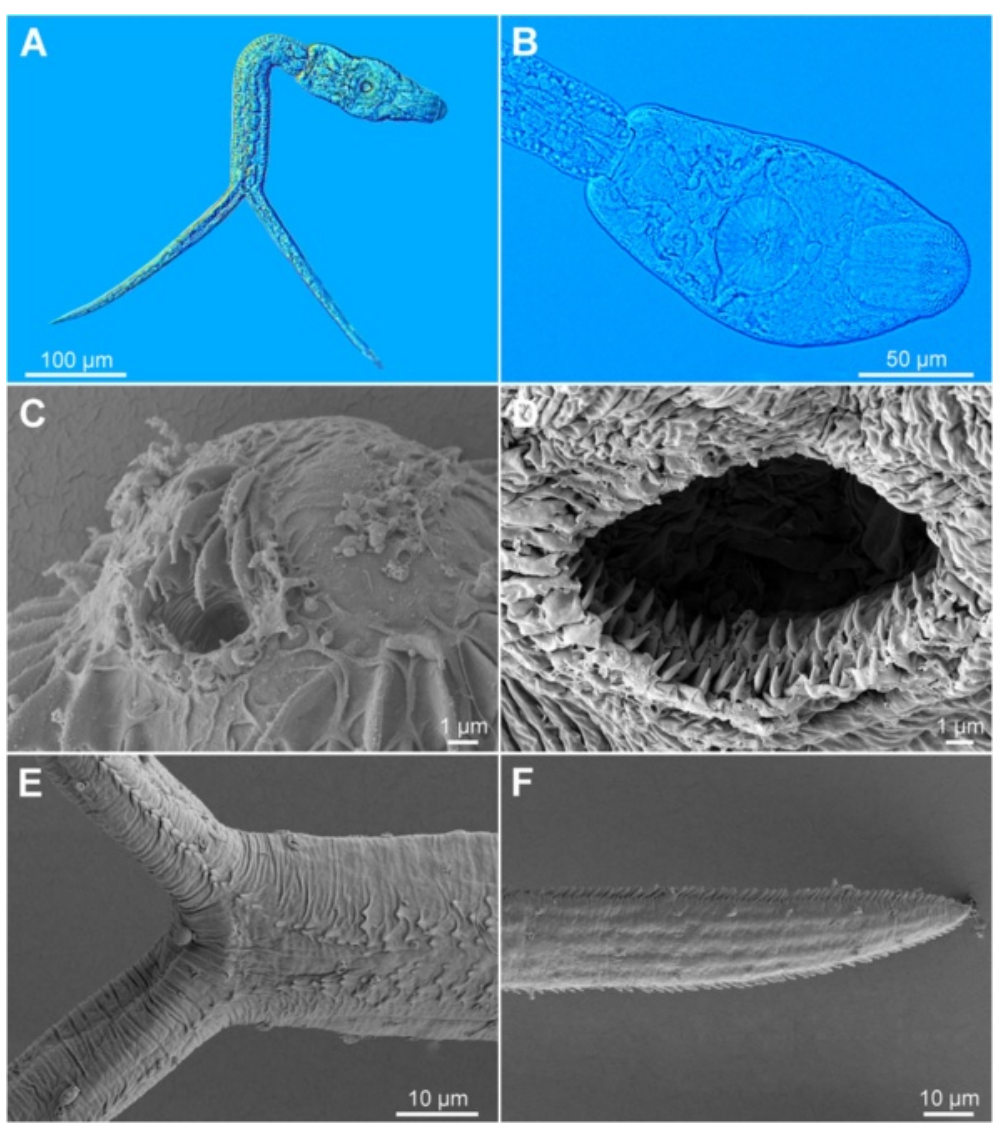

Fig. 5 Cercaria of Diplostomum parviventosum ex Radix auricularia (light and scanning electron microscopy, SEM). a, Resting position; b, Body; c, Anterior organ, apical view (SEM); d, Ventral sucker (SEM); e, Tail stem and furcae (SEM); f, Furcae (SEM)

Table 5 Comparative metrical data for cercariae of the Diplostomum 'mergi' species complex

\begin{tabular}{|c|c|c|c|c|c|}
\hline Species & D. mergi & 'D. mergi Lineage 2' & 'D. mergi Lineage 3 ' & D. parviventosum & \\
\hline Source & Niewiadomska \& Kiselienè [10] & Present study & Present study & Niewiadomska \& Kiselienè [10] & Present study \\
\hline Fixation method & Heat-killed in water & Formalin & Formalin & Heat-killed in water & Formalin \\
\hline $\mathrm{BL}$ & $161-204(182)$ & $157-179(168)$ & 171-191 (184) & 162-185 (176) & $115-151(134)$ \\
\hline BW & $51-68(59)$ & $62-67(64)$ & $44-54(49)$ & $50-70(55)$ & $50-61(54)$ \\
\hline $\mathrm{AOL}$ & $51-68(58)$ & $43-53(49)$ & $42-59(48)$ & $55-60(56)$ & $43-53(47)$ \\
\hline AOW & $25-30(28)$ & $24-36(33)$ & $29-35(32)$ & $29-32(31)$ & $26-33(30)$ \\
\hline VSL & $34-51(44)$ & $43-49(46)$ & $28-33(31)$ & $34-38(36)$ & 29-39 (33) \\
\hline VSW & $34-51(44)$ & $50-56(53)$ & $28-35(32)$ & $34-37(36)$ & $30-46(37)$ \\
\hline TSL & $187-229(207)$ & $146-180(168)$ & $196-224(212)$ & $203-242(228)$ & $153-176(165)$ \\
\hline TSW & $34-43(36)$ & $27-32(29)$ & $30-36(33)$ & $31-40(35)$ & $26-36(30)$ \\
\hline $\mathrm{FL}$ & $187-229(210)$ & $203-227(216)$ & $210-245(225)$ & $191-218(206)$ & $178-217(204)$ \\
\hline VSW/AOW & (1.6) & $1.5-2.1(1.6)$ & $0.9-1.1(1.0)$ & $(1.1)$ & $1.0-1.4(1.2)$ \\
\hline $\mathrm{BL} / \mathrm{TSL}$ & $(0.9)$ & $1.0-1.1(1.0)$ & $0.8-1.0(0.9)$ & $(0.8)$ & $0.7-0.9(0.8)$ \\
\hline TSL/FL & (1.0) & $0.7-0.8(0.8)$ & $0.9-1.0(0.9)$ & $(1.1)$ & $0.8-0.9(0.8)$ \\
\hline
\end{tabular}

Data are presented as the range followed by the mean in parentheses. See Methods and Additional file 1: Figure S1 for description and illustration of the metrical features 
(1.2)]. Penetration gland-cells 2 pairs, relatively small, with fine granular content, posterior to ventral sucker, overlap caeca partially, posterior pair not reaching extremities of caeca; ducts open antero-laterally to mouth. Tail stem 148 - 208 (173) long, 27 - 40 (33) wide at base, slightly shorter than furcae $[\mathrm{TSL} / \mathrm{FL}=0.7-1.0(0.8)]$, contains $10-12$ pairs of caudal bodies, irregularly shaped but with smooth contours. Furcae 199 - 234 (216) long, with fish-fin like fin-folds.

Body armature: Pre-oral spines arranged in median group of 6-7 spines in 3 rows; lateral groups absent (Fig. 5c, Additional file 3: Figure S2A). Post-oral spines more robust than spines on body, in $7-8$ alternate rows; rows $1-2$ with median interruption; first 4 spines in row 1 on both sides of median interruption largest; spines in row 1 larger than remaining spines, all of similar size. Wide zone of smaller, less dense, irregularly dispersed spines present posterior to post-oral spines, followed by narrow spineless area and 11 transverse rows of spines extending to mid-level of ventral sucker. Rows $1-4$ complete (i.e. encircling body); rows 5-8 discontinuous dorsally; rows 9-11 discontinuous ventrally and dorsally; rows 1 and 10 with additional spines laterally. Two ventro-lateral fields of smaller spines (0.81.2) present posterior to ventral sucker; fields converge close to posterior extremity of body. Ventral sucker armed with 2 rows of spines (c.40 per row; range 77 87; mean 81) (Fig. 5d, Additional file 4: Figure S3A). Tail stem and furcae with scale-like spines (Fig. 5e); spines on tail stem in 4 medio-lateral bands (2 ventral and 2 dorsal), each consisting of $2-3$ scale-like spines, increasing in size posteriorly $(0.6-2)$, plus a median row of minute spines; bands continue along furcal margins as rows of 2 spines anteriorly and single spine posteriorly; all spines on furcae enveloped by tegumental membrane forming fish-fin like fin-fold (Fig. 5f, Additional file 5: Figure S4A).

Resting position: Tail stem bent at $<90^{\circ}\left(45-67^{\circ}\right)$.

'Diplostomum mergi Lineage 2' of Georgieva et al. [6] First intermediate host: Radix auricularia (Linnaeus). Locality: Hengsteysee, Sorpetalsperre, Germany.

[Figure 6 and Additional file 3: Figure S2C, Additional file 4: Figure S3C, Additional file 5: Figure S4C. Measurements from formalin-fixed specimens are provided in Table 5.] Body elongate-oval, 154-179 ×60-66 $(167 \times 63)$, slightly shorter than tail stem $[\mathrm{BL} / \mathrm{TSL}=0.8$ $-0.9(0.9)$ ], with aggregations of yellow pigment in parenchyma on both sides of terminal organ and around ventral sucker, most prominently anterior to ventral sucker (Fig. 6a, b). Anterior organ elongate-oval, with posterior margin reaching to mid-length of forebody, 50 $-62 \times 26-30 \quad(56 \times 28)$. Ventral sucker subspherical, large, somewhat post-equatorial, $47-53 \times 42-52(50 \times$
47), with fine undulating membrane (3 - 4 high) (Fig. 6d); width exceeds width of anterior organ [VSW/AOW = $1.5-2.0$ (1.7)]. Penetration gland-cells 2 pairs, large, with fine granular content, posterior to ventral sucker, overlap caeca partially, posterior pair not reaching extremities of caeca; ducts open antero-laterally to mouth. Tail stem 185 - 207 (195) long, 31 - 36 (33) wide at base, shorter than furcae $[\mathrm{TSL} / \mathrm{FL}=0.8-0.9(0.8)]$, contains 36 - 40 caudal bodies; individual caudal bodies with smooth contours. Furcae 221 - 273 (247) long, with fishfin like fin-folds.

Body armature: Pre-oral spines arranged in median group of $5-6$ spines in 2 rows with one median spine very large (Fig. 6c, Additional file 3: Figure S2C); one additional very small spine may be present; lateral groups absent. Post-oral spines more robust than spines on body, in 11 alternate rows (one additional median row may be present); rows $1-2$ with median interruption; first 4 spines in row 1 and first 3 spines in row 2 on both sides of median interruption largest; spines in row 1 larger than remaining spines, all of similar size. Wide zone of smaller, less dense, irregularly dispersed spines present posterior to post-oral spines, followed by narrow spineless area and 10 transverse rows of spines extending to mid-level of ventral sucker; row 10 with smaller and fewer spines. Rows $1-5$ complete (i.e. encircling body); rows 6-10 discontinuous ventrally and dorsally; rows $1-4$ with additional spines laterally; rows 5 and 6 with few additional spines laterally. Two ventrolateral fields of smaller spines (1.0-1.5) present posterior to ventral sucker; fields converge close to posterior extremity of body. Ventral sucker armed with 2 rows of spines (c.57 per row; range 110 - 120; mean 114) (Fig. 6d, Additional file 4: Figure S3C). Tail stem and furcae with scale-like spines (Fig. 6e); spines on tail stem in 4 medio-lateral bands (2 ventral and 2 dorsal), starting from second quarter of tail, each consisting of 2-3 scale-like spines, increasing in size posteriorly $(0.6-2.5)$; bands continue along furcal margins as rows of 2 spines anteriorly and 1 spine posteriorly; all spines on furcae enveloped by tegumental membrane forming fish-fin like fin-fold (Fig. 6f, Additional file 5: Figure S4C).

Resting position: Tail stem bent at $<90^{\circ}\left(64-85^{\circ}\right)$.

\section{'Diplostomum mergi Lineage 3' of Georgieva et al. [6]} First intermediate host: Radix auricularia (Linnaeus). Locality: Hengsteysee, Germany.

[Figure 7 and Additional file 3: Figure S2D, Additional file 4: Figure S3D, Additional file 5: Figure S4D. Measurements of formalin-fixed specimens are provided in Table 5.] Body elongate-oval, $158-169 \times 50-57(162 \times$ $53)$, slightly shorter than tail stem $[\mathrm{BL} / \mathrm{TSL}=0.9-1.0$ (0.9)], with aggregations of yellow pigment in parenchyma on both sides of ventral sucker (Fig. 7a, b). Anterior organ 

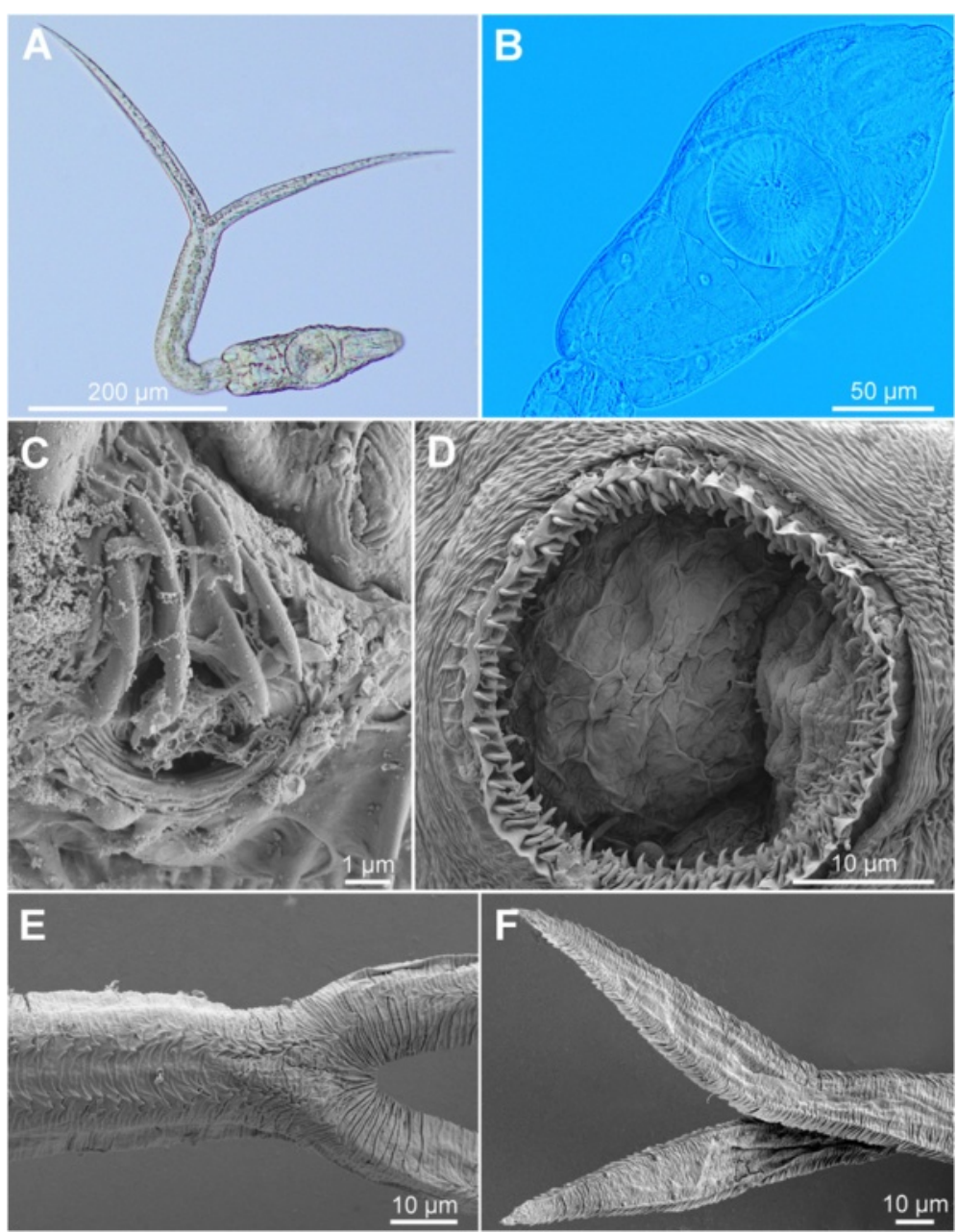

Fig. 6 Cercaria of 'Diplostomum mergi Lineage 2' of Georgieva et al. [6]) ex Radix auricularia (light and scanning electron microscopy, SEM). a, Resting position; b, Body; c, Anterior organ, apical view (SEM); d, Ventral sucker (SEM); e, Tail stem and furcae (SEM); f, Furcae (SEM)

elongate-oval, with posterior margin reaching to midlength of forebody, $50-57 \times 26-29(54 \times 28)$. Ventral sucker spherical, small, somewhat post-equatorial, 29 $34 \times 28-32(31 \times 31)$, with fine undulating membrane $(2$ high) (Fig. 7d); width slightly exceeds width of anterior organ $[\mathrm{VSW} / \mathrm{AOW}=1.0-1.2(1.1)]$. Penetration glandcells 2 pairs, medium-sized, with fine granular content, posterior to ventral sucker, overlap caeca partially, posterior pair not reaching extremities of caeca, ducts open antero-laterally to mouth. Tail stem $167-197$ (179) long, $31-33$ (32) wide at base, shorter than furcae [TSL/FL = $0.7-0.8(0.8)]$, contains numerous (impossible to count) caudal bodies with incised contours. Furcae 215-240 (227) long, with fish-fin like fin-folds.

Body armature: Pre-oral spines arranged in median group of 7 spines in 3 rows with one median spine slightly larger (Fig 7c, Additional file 3: Figure S2D); lateral groups absent. Post-oral spines more robust than spines on body, in 10 alternate rows; rows $1-2$ with a median interruption; first 4 spines in row 1 on both sides of median interruption largest; spines in rows $1-2$ larger than remaining spines, all of similar size. Wide zone of smaller, less dense, irregularly dispersed spines present posterior to post-oral spines, followed by narrow spineless area and 11 transverse rows of spines extending to mid-level of ventral sucker; row 11 with smaller spines. Rows $1-3$ complete (i.e. encircling body); rows 4-11 discontinuous ventrally and dorsally; row 1 doubled; rows $2-3$ with additional spines laterally. Two ventro-lateral non-converging fields of smaller spines $(0.7-1.0)$ present posterior to ventral sucker. Ventral sucker armed with 2 rows of spines (c.45 per row; range 90 - 92; mean 90) (Fig. 7d, Additional file 4: Figure S3D). Tail stem and furcae with scale-like spines (Fig. 7e); spines on tail stem in 4 medio-lateral bands (2 ventral and 2 dorsal), each consisting of $2-3$ scale-like spines, increasing in size posteriorly $(0.8-3.0)$; bands continue along furcal margins as rows of 2 spines anteriorly and 1 

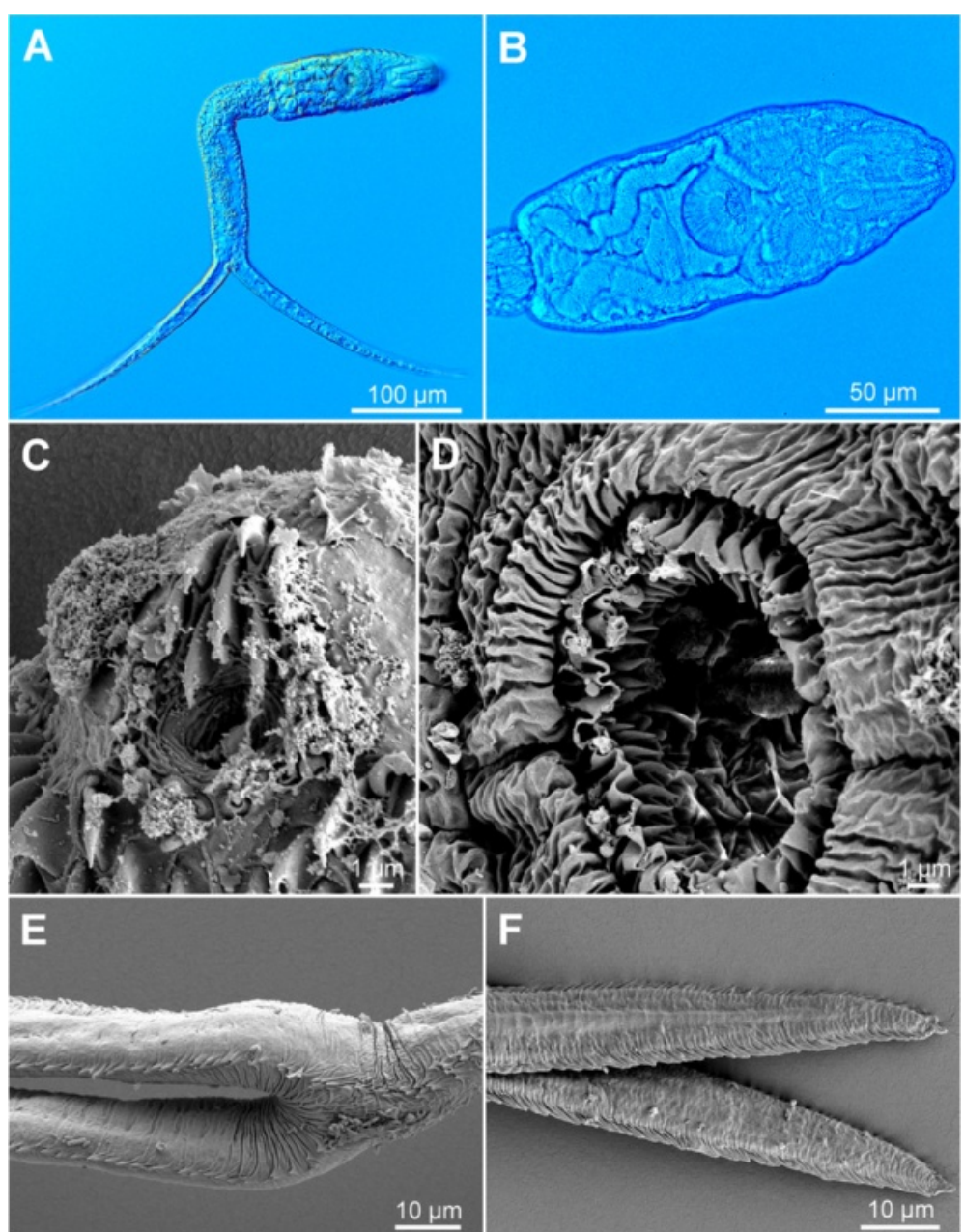

Fig. 7 Cercaria of 'Diplostomum mergi Lineage 3' of Georgieva et al. [6] ex Radix auricularia (light and scanning electron microscopy, SEM). a, Resting position; b, Body; c, Anterior organ, apical view (SEM); d, Ventral sucker (SEM); e, Tail stem and furcae (SEM); f, Furcae (SEM)

spine posteriorly; all spines on furcae enveloped by tegumental membrane forming fin-fold (Fig. 7f, Additional file 5: Figure S4D).

Resting position: Tail stem bent at $\leq 90^{\circ}\left(77-91^{\circ}\right)$.

\section{Diplostomum mergi Lineage 4}

First intermediate host: Radix auricularia (Linnaeus).

Locality: Hengsteysee, Germany.

[Figure 8 and Additional file 3: Figure S2B, Additional file 4: Figure S3B, Additional file 5: Figure S4B.] Body elongate-oval, $180-186 \times 94-115(184 \times 105)$, shorter than tail stem $(\mathrm{BL} / \mathrm{TSL}=0.7)$, with aggregations of yellow pigment in parenchyma on both sides of terminal organ and around ventral sucker (Fig. 8a, b). Anterior organ elongate-oval, with posterior margin reaching to mid-length of forebody, $54-74 \times 38-51(63 \times 44)$. Ventral sucker transversely oval, large, somewhat post-equatorial, $58-79 \times 65-78(63 \times 71)$, with fine undulating membrane (3-5 high) (Fig. $8 d$ ); width exceeds width of anterior organ [VSW/AOW = $1.5-1.7$ (1.6)]. Penetration gland-cells 3 pairs (anterior pair small, posterior pairs large), with fine granular content, posterior to ventral sucker, overlap caeca partially, posterior pair not reaching extremities of caeca; ducts open antero-laterally to mouth. Tail stem 261 - 263 (262) long, $41-47$ (43) wide at base, of equal length as furcae (TSL/FL = 1.0), with 36 - 40 caudal bodies; individual caudal bodies irregularly shaped with smooth contours. Furcae 269 long, with fish-fin like fin-folds.

Body armature: Pre-oral spines arranged in median group of 7 spines in 3 rows with one median spine very large (Fig. 8c, Additional file 3: Figure S2B); lateral groups absent. Post-oral spines more robust than spines on body, in 11 alternate rows; rows $1-2$ with median interruption, rows 10-11 interrupted dorsally; first 4 spines in row 1 and first 3 spines in row 2 on both sides of median interruption largest; spines in first 2 rows larger than remaining spines, all of similar size. Wide zone of smaller, less dense, irregularly dispersed spines 


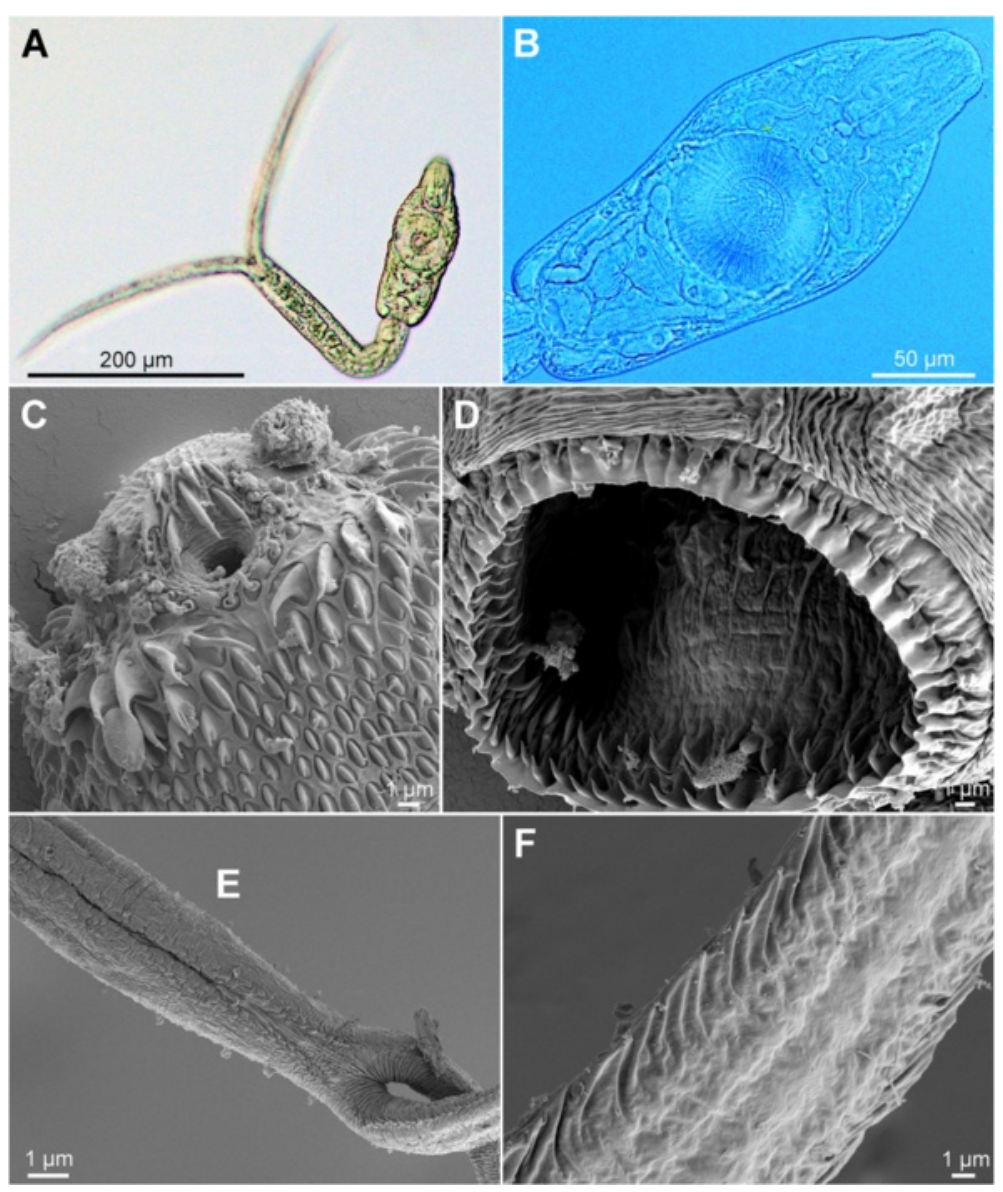

Fig. 8 Cercaria of Diplostomum mergi Lineage 4 ex Radix auricularia (light and scanning electron microscopy, SEM). a, Resting position; b, Body; c, Anterior organ, apical view (SEM); d, Ventral sucker (SEM); e, Tail stem and furcae (SEM); f, Furcae (SEM)

present posterior to post-oral spines, followed by narrow spineless area and 10 transverse rows of spines extending to mid-level of ventral sucker. Rows $1-4$ complete (i.e. encircling body); rows $5-7$ discontinuous dorsally; rows 8-10 discontinuous ventrally and dorsally. Two ventro-lateral fields of smaller spines (0.5-1.0) present posterior to ventral sucker; fields converge close to posterior extremity of body. Ventral sucker armed with 2 rows of spines (c.56 per row; range 112 - 114; mean 113) (Fig. 8d, Additional file 4: Figure S3B). Tail stem and furcae with scale-like spines (Fig. 8e); spines on tail stem in 4 medio-lateral bands ( 2 ventral and 2 dorsal), each consisting of $1-2$ scale-like spines, increasing in size posteriorly $(1-3)$; bands continue along furcal margins as single rows of spines; all spines on furcae enveloped by tegumental membrane forming fish-fin like fin-fold (Fig. 8f, Additional file 5: Figure S4B).

Resting position: Tail stem bent at $<90^{\circ}\left(66^{\circ}\right)$.

'Diplostomum sp. Clade Q' of Georgieva et al. [6] First intermediate host: Radix auricularia (Linnaeus). Locality: Hengsteysee, Germany.
[Figure 9 and Additional file 4: Figure S3E, Additional file 5: Figure S4E.] Body elongate-oval, $215-239 \times 87-$ $101(224 \times 96)$, shorter than tail stem $(B L / T S L=0.8)$, with aggregations of yellow pigment in parenchyma on both sides of terminal organ, around ventral sucker (Fig. 9a) and in furcae. Anterior organ elongate-oval, with posterior margin reaching to mid-length of forebody, $70-88 \times 46-48(80 \times 47)$. Ventral sucker transversely oval, large, somewhat post-equatorial, $51-60 \times$ $57-70(56 \times 65)$, with fine undulating membrane (5 high) (Fig. 9d); width exceeds width of anterior organ [VSW/AOW $=1.2-1.4$ (1.3)]. Penetration gland-cells 2 pairs, large, with fine granular content, posterior to ventral sucker, overlap caeca partially, posterior pair not reaching extremities of caeca; ducts open antero-laterally to mouth. Tail stem 266 long, $43-48$ (46) wide at base, of equal length to furcae (TSL/FL $=1.0$ ), contains 10 pairs of caudal bodies with incised contours. Furcae 280 long, with fish-fin like fin-folds.

Body armature: Pre-oral spines arranged in median group of 9 spines in 3 rows (Fig. 9c); lateral groups absent. Post-oral spines more robust than spines on body, 

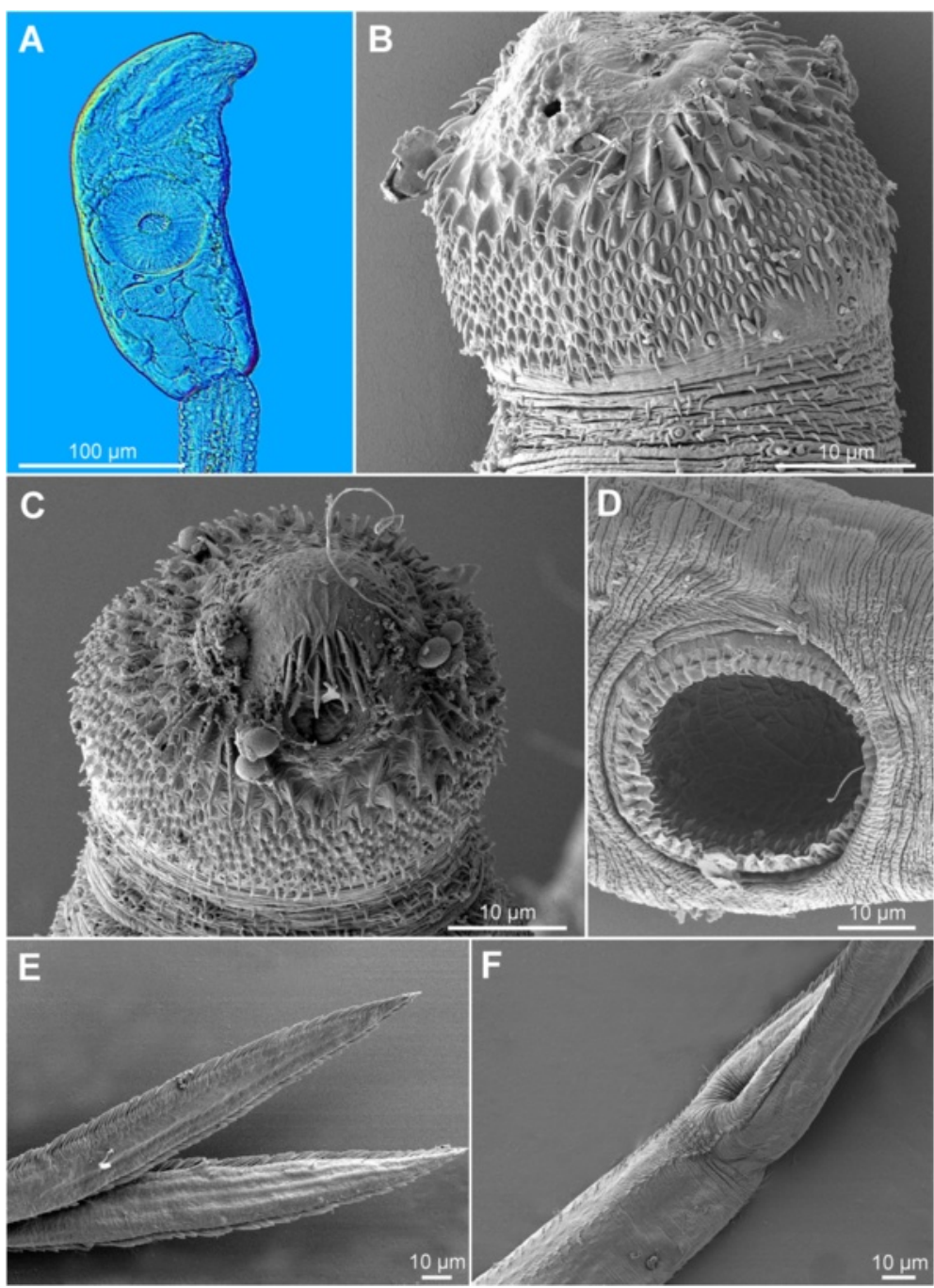

Fig. 9 Cercaria of 'Diplostomum sp. Clade Q' of Georgieva et al. [6] ex Radix auricularia (light and scanning electron microscopy, SEM). a, Body; b, Anterior organ, lateral view (SEM); c, Anterior organ, apical view (SEM); d, Ventral sucker (SEM); e, Furcae (SEM); f, Tail stem and furcae (SEM)

in 12 alternate rows; first row with median interruption, rows 11-12 interrupted laterally; first 5 spines in row 1 on both sides of median interruption largest; remaining spines of different sizes, spines in rows 1-4 distinctly larger than those in remaining rows, spines in rows 510 small, spines in rows 10-12 medium-sized (Fig. 9b). Wide zone of smaller, less dense, irregularly dispersed spines present posterior to post-oral spines (spines sparser dorsally), followed by narrow spineless area and 10 transverse rows of spines extending to mid-level of ventral sucker. Rows $1-4$ complete (i.e. encircling body); rows 5-10 discontinuous ventrally and dorsally; row 1 doubled, rows $2-3$ with additional spines laterally. Two ventro-lateral non-converging fields of smaller spines (0.71.3) present posterior to ventral sucker. Ventral sucker armed with 2 rows of spines (c.57 per row; range 112 116; mean 114) (Fig. 9d, Additional file 4: Figure S3E). Tail stem and furcae with scale-like spines (Fig. 9f); spines on tail stem in 4 medio-lateral bands (2 ventral and 2 dorsal), each consisting of $1-2$ scale-like spines anteriorly and of 3 spines posteriorly close to bifurcation; spines increase in size posteriorly $(0.6-3.0)$; bands continue along furcal margins as single rows of spines; all spines on furcae enveloped by tegumental membrane forming fish-fin like fin-folds (Fig. 9e, Additional file 5: Figure S4E).

Resting position not observed.

\section{Diplostomum spathaceum (Rudolphi, 1819)}

First intermediate host: Radix auricularia (Linnaeus).

Locality: Hengsteysee, Germany.

[Figure 10 and Additional file 3: Figure S2G, Additional file 4: Figure S3G, Additional file 5: Figure S4G. Measurements of formalin-fixed specimens are provided in Table 6.] Body elongate-oval, $159-178 \times 46-60(172 \times$ 


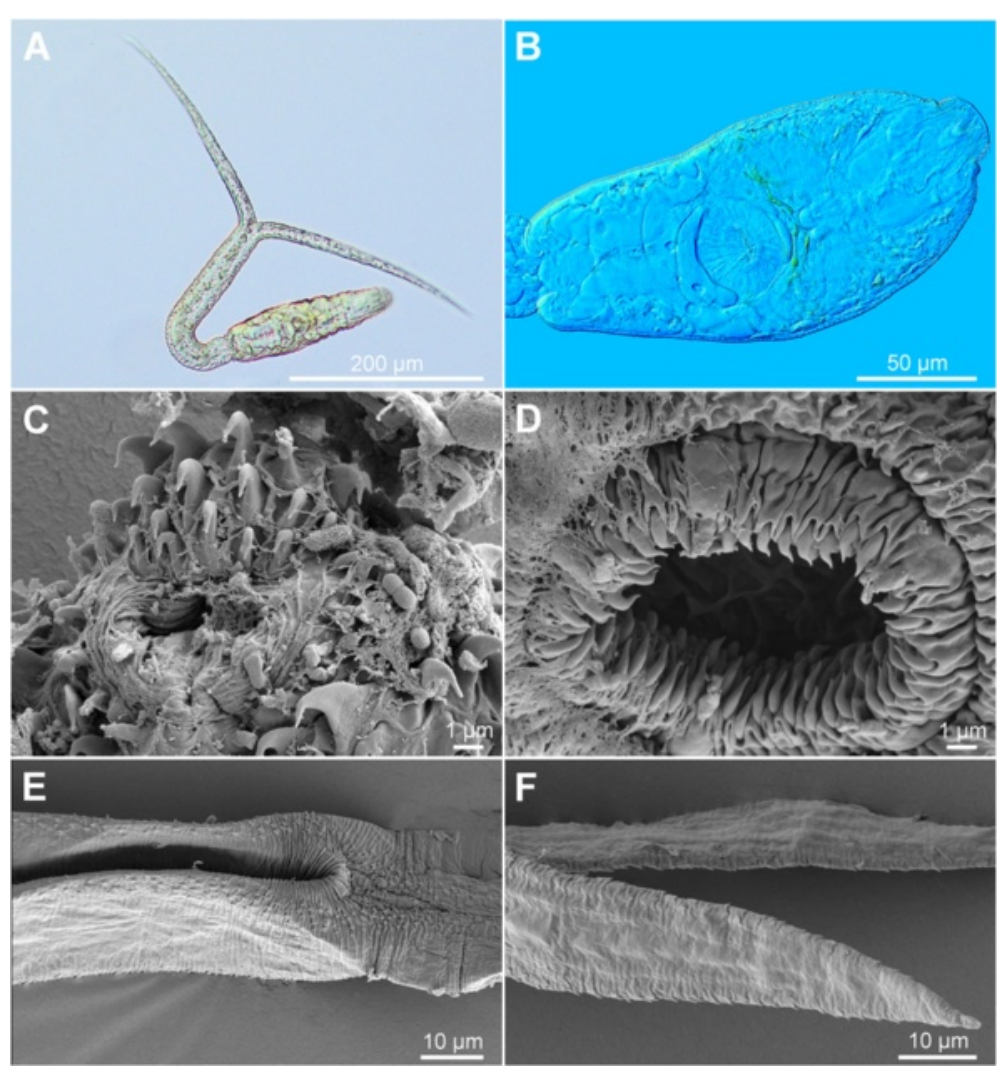

Fig. 10 Cercaria of Diplostomum spathaceum ex Radix auricularia (light and scanning electron microscopy, SEM). a, Resting position; b, Body; c, Anterior organ, apical view (SEM); d, Ventral sucker (SEM); e, Tail stem and furcae (SEM); f, Furcae (SEM)

51), shorter than tail stem $[\mathrm{BL} / \mathrm{TSL}=0.7-0.9(0.8)]$, with aggregations of yellow pigment in parenchyma concentrated on both sides of anterior organ and above ventral sucker (Fig. 10a, b). Anterior organ elongate-oval, with posterior margin reaching to mid-length of forebody, 39 $56 \times 24-28(50 \times 26)$. Ventral sucker spherical, small, somewhat post-equatorial, $26-35 \times 27-33(30 \times 30)$, with fine undulating membrane ( $2-3.5$ high) (Fig. 10d); width slightly exceeds width of anterior organ [VSW/ $\mathrm{AOW}=1.0-1.3(1.1)]$. Penetration gland-cells 2 pairs, large, with fine granular content, posterior to ventral sucker, overlap caeca partially, posterior pair not reaching extremities of caeca. Tail stem 197 - 233 (219) long, 29 32 (31) wide at base, shorter than furcae [TSL/FL $=0.8-$ $0.9(0.8)$ ], contains 56 - 60 caudal bodies; individual caudal bodies irregularly shaped with both incised and smooth contours. Furcae 250 - 267 (260) long, without fin-fold.

Body armature: Pre-oral spines arranged in median group of $18-19$ spines in 3 rows (Fig. 10c, Additional file 3: Figure S2G); spines in most anterior row largest, gradually decreasing in size in remaining rows; 2 lateral groups with 1 small spine each present. Post-oral spines more robust than spines on body, in 9 alternate rows; row 1 with median interruption; row 9 interrupted laterally; spines in row 1 larger than remaining spines, all of similar size. Wide zone of smaller, less dense, irregularly dispersed spines present posterior to post-oral spines, followed by narrow spineless area and 10 transverse rows of spines extending to mid-level of ventral sucker. Rows $1-8$ complete (i.e. encircling body); rows 9 - 10 discontinuous ventrally; rows $1-2$ doubled ventrally; row 3 with additional spines laterally. Two ventrolateral fields of smaller spines (1.0-1.5) present posterior to ventral sucker; fields reach up to margin of ventral sucker and transverse row 10 laterally and dorsally and converge posterior to ventral sucker and close to posterior extremity of body. Ventral sucker armed with 3 rows of irregularly positioned spines (range $103-119$; mean 110) (Fig. 10d, Additional file 4: Figure S3G). Tail stem and furcae with scale-like spines; spines on tail stem in 4 medio-lateral bands ( 2 ventral and 2 dorsal), each consisting of 3 scale-like spines $(<1.0)$ (Fig. 10e); bands continue along furcal margins as rows of 4 spines anteriorly and single rows of spines posteriorly (Fig. 10f, Additional file 5: Figure S4G).

Resting position: Tail stem bent at $<45^{\circ}\left(39^{\circ}\right)$. 
Table 6 Comparative metrical data for cercariae of Diplostomum pseudospathaceum, D. spathaceum and D. paracaudum

\begin{tabular}{|c|c|c|c|c|c|}
\hline Species & D. pseudospathaceum & & D. spathaceum & D. paracaudum & D. spathaceum \\
\hline Source & $\begin{array}{l}\text { Niewiadomska [27]; } \\
\text { Niewiadomska \& Kiselienè [10] }\end{array}$ & Present study & $\begin{array}{l}\text { Niewiadomska [27]; } \\
\text { Niewiadomska \& Kiselienè [10] }\end{array}$ & $\begin{array}{l}\text { Niewiadomska [28]; } \\
\text { Niewiadomska \& Kiselienè [10] }\end{array}$ & Present study \\
\hline Fixation method & Heat-killed in water & Formalin & Heat-killed in water & Heat-killed in water & Formalin \\
\hline $\mathrm{BL}$ & 170-199 (185) & $150-172(162)$ & $222-288(235)$ & 185-199 (189) & 155-181 (170) \\
\hline BW & $44-51(45)$ & $57-64(59)$ & $66-81(73)$ & $44-51(46)$ & $50-58(53)$ \\
\hline $\mathrm{AOL}$ & 40-51 (49) & $43-51(47)$ & $61-95(68)$ & $51-54(51)$ & $33-50(45)$ \\
\hline AOW & $25-27(27)$ & $28-34(31)$ & $30-40(34)$ & $23-30(27)$ & 28-33 (30) \\
\hline VSL & 23-30 (29) & 19-31 (28) & $47-68(53)$ & $23-30(25)$ & 29-31 (31) \\
\hline VSW & 23-34 (28) & $26-33(30)$ & $51-68(59)$ & $27-30(28)$ & $25-31(27)$ \\
\hline TSL & 199-214 (206) & $203-221(213)$ & 244-303 (273) & $185-222(211)$ & $241-260(250)$ \\
\hline TW & 29-31 (29) & $21-32(29)$ & $40-44(44)$ & 37 & $30-34(32)$ \\
\hline $\mathrm{FL}$ & $185-222(201)$ & $212-246(232)$ & $251-296(273)$ & $185-222(208)$ & $237-261(252)$ \\
\hline VSW/AOW & $(1.0)$ & $0.8-1.1(1.0)$ & $(1.7)$ & $(1.0)$ & $0.8-1.1(0.9)$ \\
\hline $\mathrm{BL} / \mathrm{TSL}$ & $(0.9)$ & $0.7-0.8(0.8)$ & $(0.9)$ & $(0.9)$ & $0.6-0.7(0.7)$ \\
\hline TSL/FL & $(1.0)$ & $0.9-1.0(0.9)$ & $(1.0)$ & $(1.0)$ & $0.9-1.0(1.0)$ \\
\hline
\end{tabular}

Data are presented as the range followed by the mean in parentheses. See Methods and Additional file 1: Figure S1 for description and illustration of the metrical features

\section{Diplostomum pseudospathaceum Niewiadomska, 1984}

First intermediate hosts: Lymnaea stagnalis (Linnaeus); Stagnicola palustris (Müller).

Localities: Baldeneysee, Hengsteysee, Germany.

[Figure 11 and Additional file 3: Figure S2E, F, Additional file 4: Figure S3F, Additional file 5: Figure S4F. Measurements of formalin-fixed specimens are provided in Table 6.] Body elongate-oval, $152-183 \times 46-54(166 \times$ $50)$, slightly shorter than tail stem $[\mathrm{BL} / \mathrm{TSL}=0.8-1.0$ (0.9)] (Fig. 11a, b), with aggregations of yellow pigment in the parenchyma of whole body, concentrated on both sides of anterior organ, above ventral sucker and in tail stem and furcae. Anterior organ elongate-oval, with posterior margin reaching to mid-length of forebody, 41 $58 \times 22-28(50 \times 25)$. Ventral sucker spherical, small, somewhat post-equatorial, $24-32 \times 27-32 \quad(29 \times 30)$, with fine undulating membrane ( $2-3$ high) (Fig. 11d); width exceeds width of anterior organ [VSW/AOW $=1.1$ - 1.4 (1.2)]. Penetration gland-cells 2 pairs, large, with fine granular content, posterior to ventral sucker, overlap caeca partially, posterior pair not reaching extremities of caeca. Tail stem 176 - 203 (187) long, 27 - 30 (29) wide at base, shorter than furcae $[\mathrm{TSL} / \mathrm{FL}=0.8-0.8(0.8)]$, contains 35 - 45 caudal bodies; individual caudal bodies irregularly shaped with smooth contours. Furcae $219-253$ (234) long, without fin-fold.

Body armature: Pre-oral spines arranged in median group of $10-11$ spines in 3 rows; spines in anterior row largest, remaining spines of similar size; 2 lateral groups with 3 small spines each present (Fig. 11c, Additional file 3: Figure S2E, F). Post-oral spines more robust than spines on body, in 9 alternate rows; rows $1-2$ with median interruption; row 9 interrupted laterally; first 2 spines in row 1 on both sides of median interruption largest; spines in row 1 larger than remaining spines, all of similar size. Wide zone of smaller, less dense, irregularly dispersed spines present posterior to post-oral spines, followed by narrow spineless area and 11 transverse rows of spines extending to mid-level of ventral sucker. Rows 1-8 complete (i.e. encircling body); row 9 discontinuous ventrally, rows $10-11$ discontinuous ventrally and dorsally; rows $1-2$ doubled ventrally; rows $3-7$ with additional spines laterally. Two ventro-lateral fields of smaller spines (1.0-1.5) present posterior to ventral sucker; fields reach up to margin of ventral sucker and transverse row 11 laterally and dorsally and converge posterior of ventral sucker and close to posterior extremity of body. Ventral sucker armed with 2 rows of spines (c.42 per row; range 70 - 100; mean 84); third row may be partially formed (Fig. 11d, Additional file 4: Figure S3F). Tail stem and furcae with scale-like spines (Fig. 11e); spines on tail stem in 4 medio-lateral bands ( 2 ventral and 2 dorsal), each consisting of 1-2 scale-like spines anteriorly, $2-3$ spines posteriorly, increasing in size posteriorly $(0.5-1.3 \mu \mathrm{m})$; bands continue along furcal margins as rows of 3 spines anteriorly and 2 spines posteriorly (Fig. 11f, Additional file 5: Figure S4F).

Resting position: Tail stem bent at $<45^{\circ}\left(29-38^{\circ}\right)$.

\section{Discussion}

To the best of our knowledge, this study provides the first combined morphological and molecular characterisation of Diplostomum spp. in natural lymnaeid snail populations in central Europe and is the first to apply 


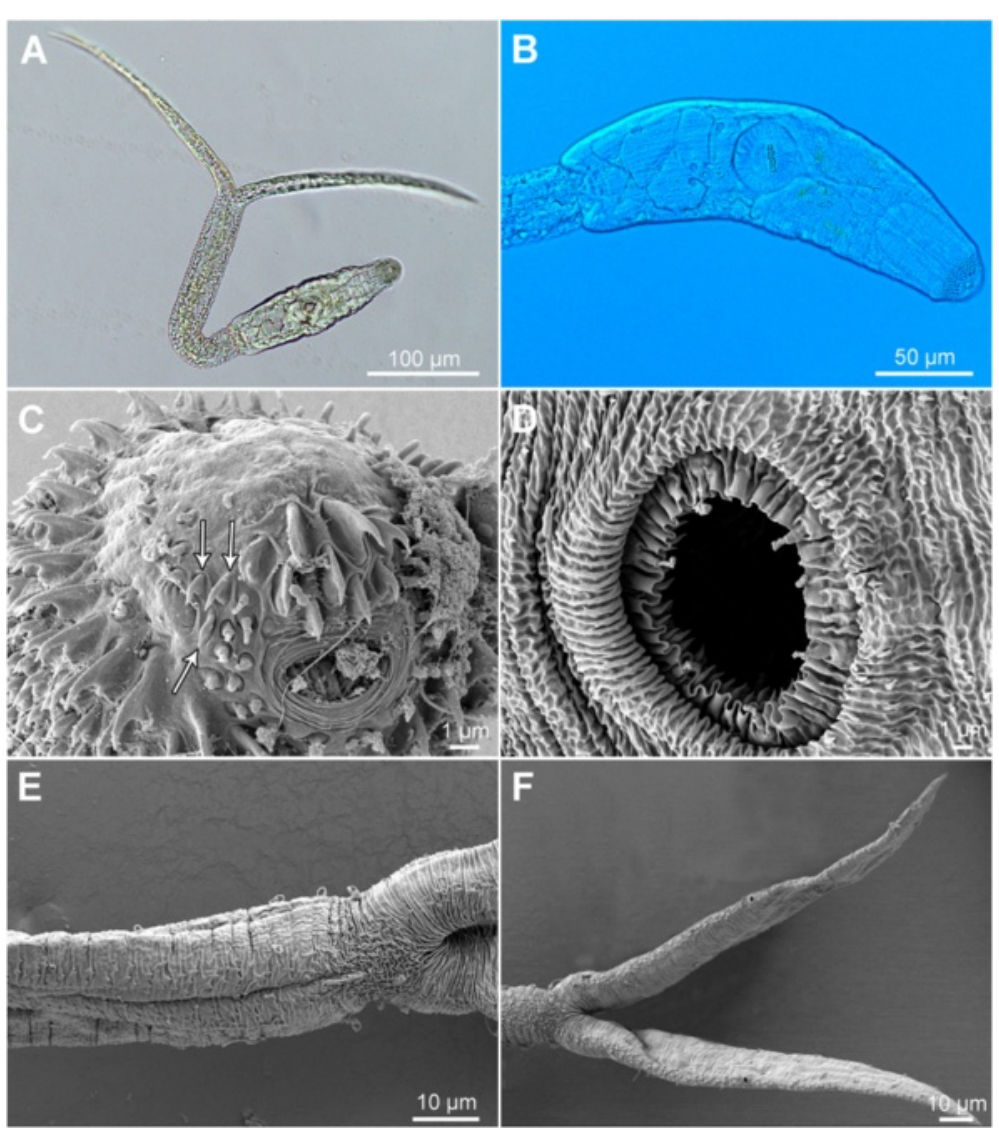

Fig. 11 Cercaria of Diplostomum pseudospathaceum ex Lymnaea stagnalis (light and scanning electron microscopy, SEM). a, Resting position; b. Body; c, Anterior organ, apical view, arrows indicate group of lateral pre-oral spines (SEM); d, Ventral sucker (SEM); e, Tail stem and furcae (SEM); f, Furcae (SEM)

thorough SEM analysis of species-specific features of the cercariae that can be used for species identification and delineation. This integrative approach allowed us to (i) provide evidence for morphological and molecular differentiation within the ' $D$. mergi' species complex, including a previously undetected lineage; (ii) clarify that 'D. mergi Lineage 1' of Georgieva et al. [6] represents $D$. parviventosum; (iii) partially elucidate the life-cycle of 'D. mergi Lineage 3' and 'Diplostomum sp. Clade Q' of Georgieva et al. [6]; (iv) expand the cox1 database for the European species $D$. pseudospathaceum and $D$. spathaceum in association with descriptions based on sequenced isolates; and (vii) assess the first intermediate host-specificity of D. pseudospathaceum.

Morphologically, the cercaria corresponding genetically to ' $D$. mergi Lineage 1' of Georgieva et al. [6] keyed down to $D$. parviventosum in the key of Niewiadomska \& Kiseliene [10] due to the presence of 6-7 pre-oral spines, 11 transverse rows of spines on the body, 10-12 pairs of caudal bodies in the tail, ventral sucker slightly exceeding the width of the anterior organ [VSW/AOW 1.0-1.4 (1.2)], fin-folds on the furcae, and small penetration gland-cells which do not cover ends of caeca (see Additional file 6: Table S2). As described for D. parviventosum by Niewiadomska \& Kiselienè [10], the present cercaria also shows a characteristic resting position with the tail stem bent at about $45^{\circ}$ but differs in having 11 transverse rows of spines on the body ( $v s$ 10); of these rows 9-11 are interrupted ventrally and dorsally and rows $5-8$ are interrupted dorsally ( $v s$ rows $6-10$ with ventral and dorsal interruption) (Additional file 6: Table S2). Comparisons of the metrical data for fixed cercariae revealed differences probably due to the fixation method (Table 5). The present cercariae (both live and formalin-fixed) exhibit lower ranges and means for the length of the body, anterior organ and tail stem, the latter resulting in a lower range for the ratio TSL/FL (mean $0.8 v s$ 1.1), and higher upper limits for the width of the ventral sucker (46 vs $37 \mu \mathrm{m})$. However, the ratios VSW/AOW and BL/TSL are similar (see means in Table 5). Furthermore, the number of rows of post-oral spines (7-8 alternate rows) and the number of spines on the ventral sucker (77-87 in two rows) agree well with the description by Niewiadomska \& Kiseliené [10], i.e. 6-8 rows of post-oral spines and $80-88$ spines on ventral 
sucker in two rows (Additional file 6: Table S2). Our study thus provides the first detailed morphological description of the cercaria of $D$. parviventosum based on both light and scanning electron microscopy. Furthermore, the concordance of the morphological and molecular data clearly suggests that the isolates of ' $D$. mergi Lineage 1' of Georgieva et al. [6] actually belong to $D$. parviventosum. However, the ITS sequences for this species generated by us formed a reciprocally monophyletic lineage within the ' $D$. mergi' species complex instead of joining the cluster of sequences ('Clade Q' sensu Georgieva et al. [6]) representative for $D$. parviventosum according to Niewiadomska \& Laskowski [23] (see also comment below).

Cercariae of the remaining three lineages of the ' $D$. mergi' species complex discovered in this study differ from the description of $D$. mergi by Niewiadomska \& Kiseliene [10] in four unique qualitative features, i.e. the presence of scale-like spines on the tail stem and furcae and of yellow pigment in the forebody, the greater number of rows of post-oral spines (10-11 vs 6-9) and in the different number of transverse rows with additional spines laterally (Additional file 6: Table S2). Cercariae of Lineages 2 and 3 of ' $D$. mergi' can be further differentiated from D. mergi of Niewiadomska \& Kiselienè [10]) by having furcae longer than tail stem ( $v s$ equal); the cercaria of ' $D$. mergi Lineage 3' also possesses 11 transverse rows of spines on body ( $v s 10$ ) and a smaller number of spines on ventral sucker (90-92 vs 94-130) and the cercaria of $D$. mergi Lineage 4 is unique in having three pairs of penetration gland-cells (Additional file 6: Table S2). Morphometric comparisons revealed that the cercariae of D. mergi Lineage 4 exhibit much higher upper ranges and means for all morphometric characters than those of the two other lineages (Lineage 1 and 2; both live and fixed samples) and those in the description of $D$. mergi by Niewiadomska \& Kiseliene [10] (Table 5). Fixed cercariae of Lineages 2 and 3 both differ from those of D. mergi as described by Niewiadomska \& Kiseliene [10] in having generally shorter (mean length $48-49$ vs $58 \mu \mathrm{m}$ ) and wider (mean width 32-33 vs $28 \mu \mathrm{m}$ ) anterior organs, narrower tail stems (mean 29-33 vs $36 \mu \mathrm{m}$ ), longer furcae (mean 216-225 vs $210 \mu \mathrm{m}$ ) that are also longer than tails (mean TSL/FL 0.8-0.9 vs 1.0), and shorter ('D. mergi Lineage 2')/ longer (' $D$. mergi Lineage 3 ') tail stems (means 160 and 212 vs $207 \mu \mathrm{m}$, respectively). Further, compared with the cercaria of $D$. mergi described by Niewiadomska \& Kiseliene [10], the cercaria of ' $D$. mergi Lineage 2' has a shorter body (mean $168 v s 182 \mu \mathrm{m}$ ), a wider ventral sucker (mean 53 vs $44 \mu \mathrm{m}$ ) and a greater ratio BL/TSL (mean 1.0 vs 0.9 ), and the cercaria of ' $D$. mergi Lineage 3 ' has a narrower body (mean 49 vs $59 \mu \mathrm{m}$ ) and a smaller ventral sucker (mean $31 \times 32$ vs $44 \times 44 \mu \mathrm{m}$ ) that is also narrower in relation to the anterior organ (mean VSW/AOW $1.0 \mathrm{vs}$ 1.6).
Overall, the isolates of the three lineages (Lineages 24) of the ' $D$. mergi' species complex described here exhibit a number of unique differentiating features (five for Lineages 2 and 4 and nine for Lineage 3; see Additional file 6: Table S2). In addition to the consistent differences in the morphometric characters and ratios (Table 5) the live cercariae of the single isolate of $D$. mergi Lineage 4 differ from those of both Lineage 2 and 3 in the relation $\mathrm{BL}<\mathrm{TSL}=\mathrm{FL}(v s \mathrm{BL} \leq \mathrm{TSL}<\mathrm{FL}$ and $\mathrm{BL} \leq \mathrm{TSL}<\mathrm{FL}$, respectively), in the pattern of incomplete transverse rows of spines on the body (ventral interruption in rows 8-10 vs $6-10$ and 4-11, respectively; dorsal interruption in rows $5-10$ vs $6-10$ and 4-11, respectively), and in the lack of transverse rows with additional lateral spines.

Both live and fixed cercariae of ' $D$. mergi Lineage 2' differ from those of ' $D$. mergi Lineage 3 ' in having wider bodies (mean 63 and $64 v s 53$ and $49 \mu \mathrm{m}$, respectively), larger ventral suckers $(50 \times 47$ vs $31 \times 31 \mu \mathrm{m}$ and $46 \times 53$ vs $31 \times 32 \mu \mathrm{m}$, respectively) that are also distinctly wider than anterior organs [ratio VSW/OSW 1.5-2.0 (1.7) vs 1.0-1.2 (1.1) and 1.5-2.1 (1.6) vs 0.9-1.1 (1.0), respectively]. The cercaria of ' $D$. mergi Lineage 2 ' further differs from the cercaria of ' $D$. mergi Lineage 3' in having 5-6 pre-oral spines of the median group located in 2 rows (vs 7 in 3 rows) with one spine very large, 11 rows of post-oral spines ( $v s 10)$ with spines in the first row larger than the remaining ( $v s$ spines in the first two rows), 10 transverse rows of spines ( $v s 11$ ), as well as in the lack of double transverse rows ( $v s$ row 1 ), in the pattern of incomplete transverse rows and in having distinctly more spines on the ventral sucker (110-120 vs 90-92) (Additional file 6: Table S2). All these differences, in association with the molecular evidence, justify the distinct status of the four lineages of the ' $D$. mergi' species complex examined by us. However, it is difficult to decide whether the description of Niewiadomska \& Kiselienè [10] (see Additional file 6: Table S2) corresponds to one of these due to the different level of detail provided in the early description of $D$. mergi and the consistent differences outlined above.

The detailed morphological and molecular data provided here further advance our knowledge of the ' $D$. mergi' species complex in several aspects. First, we have clarified that ' $D$. mergi Lineage 1' of Georgieva et al. [6] in fact represents $D$. parviventosum. These authors provided sequence data for a single isolate ex $R$. auricularia from Hengsteysee thus making decisions of its relationships difficult, whereas our study provides ample evidence for the distinct status of this lineage, its identification to the species level and the detection of its relatively high prevalence in $R$. auricularia in Hengsteysee, and probably elsewhere in Europe. Our study further expands the number of isolates of ' $D$. mergi Lineage 2' ex $R$. auricularia and its distribution in Baldeneysee, Hengsteysee and Sorpetalsperre. Finally, we provide the first link between 
sequences for ' $D$. mergi Lineage 3 ' from isolates of metacercariae in the second intermediate host (Salmo trutta fario and Gobio gobio from the River Ruhr; see Georgieva et al. [6]) and a number of isolates from the first intermediate hosts ( $R$. auricularia from Hengsteysee) thus partially elucidating the life-cycle of this lineage (arguably species). Further efforts should be focused on the discovery of the adult stages and formal descriptions of the three novel lineages (Lineages 2, 3 and 4 ) of the ' $D$. mergi' species complex.

Two ITS1-5.8S-ITS2 sequences for D. mergi (sensu lato) have been published recently by Haarder et al. [18] from cercarial isolates ex Radix balthica (L.) in Denmark. These authors have shown experimentally that the cercariae infect Oncorhynchus mykiss (Walbaum). Faltýnková et al. [8] suggested, based on analysis of ITS1 only, that one of the isolates (JX494231) may belong to 'D. mergi Lineage 2' whereas the second (JX494233) appeared associated with 'D. mergi Lineage 3'. In our analyses based on the entire ITS gene cluster one of the isolates (JX494231) clustered together with the single isolate of $D$. mergi Lineage 4 (however with low support) and the other clustered with isolates of ' $D$. mergi Lineage 2'. Analysis of cox 1 sequences for these two isolates would help reveal their actual assignment.

Our study expanded the cox 1 database for European D. pseudospathaceum and D. spathaceum (18 and 7 isolates, respectively). The new isolates of both species clustered together with the isolates reported previously by Georgieva et al. [6] with high support. Based on all sequence data available to date, we can confidently suggest that $D$. pseudospathaceum completes its life-cycle using only L. stagnalis and S. palustris as first intermediate hosts and that the latter two hosts are infected only with this species. The two isolated records of $D$. pseudospathaceum ex $R$. auricularia (see $[24,25]$ ) most probably represent misidentifications. The lack of infections with $D$. pseudospathaceum in more than $3,500 R$. auricularia examined in the River Ruhr drainage ([26]; present study) provides further support for this suggestion. Morphologically, the cercarial isolates sequenced here generally (excluding the number of caudal bodies) key down to $D$. pseudospathaceum in the key of Niewiadomska \& Kiselienè [10]. However, our detailed description (including SEM examination) of the cercaria revealed some differences compared with the data provided by these authors that generally show a wider range of variation: 10-11 pre-oral spines in the median group (vs 8-14); 3 pre-oral spines in each lateral group (vs 1-4); 9 post-oral rows of spines (vs 6-8); 11 transverse rows of spines on body (vs 10); transverse rows 3-7 with additional spines laterally ( $v s$ rows $3-4$ ); spines present on entire tail stem ( $v s$ present at distal end of the tail stem); and resting position with tail stem bent at $<45^{\circ}\left(v s\right.$ at $90^{\circ}$ ) (see
Additional file 6: Table S3). Morphometric comparisons revealed that both live and formalin-fixed cercariae described here possess shorter and wider bodies (means $166 \times 50$ and $162 \times 59 \mu \mathrm{m}$, respectively, $v s 185 \times 45 \mu \mathrm{m})$, longer furcae (means 234 and $232 \mu \mathrm{m}$, respectively, $v s$ $201 \mu \mathrm{m})$, the latter resulting in somewhat lower TSL/FL ratios (means 0.8 and 0.9 , respectively, vs 1.0). Fixed cercariae described by us further exhibit greater width of the anterior organ (mean 31 vs $27 \mu \mathrm{m}$ ) and length of the tail stem (mean 213 vs $206 \mu \mathrm{m}$ ) and a lower BL/TSL ratio (mean 0.8 vs 0.9) (Table 6). These data indicate that SEM examination and adequate fixation should be considered for identification of the cercariae of D. pseudospathaceum in future studies.

This study is the first to provide a description of molecularly identified cercarial isolates of $D$. spathaceum. Both live and formalin-fixed isolates of $D$. spathaceum studied by us exhibit smaller dimensions for the size of the body, tail and all organs compared with the description of the cercaria of $D$. spathaceum by Niewiadomska [27] (the same data from 10 heat-fixed specimens were reiterated by Niewiadomska \& Kiselienè [10]) (Table 6). Qualitative comparisons revealed that our isolates possess a slightly greater number of pre-oral spines (18-19 vs 8-16 in the median group and 1 in each lateral group $v s$ no lateral spines), a smaller number of post-oral spines (9 vs 10-14), three spine rows on ventral sucker ( $v s$ 2), spined tail stem and furcae ( $v s$ unspined) and a smaller angle of bending of the tail stem in resting position $\left(<45^{\circ} v s 90^{\circ}\right)$ (see Additional file 6: Table S3).

The cercaria of $D$. spathaceum described above exhibits similarities with the description of $D$. paracaudum by Niewiadomska [28] reiterated by Niewiadomska \& Kiseliene [10] such as: an overlap in the number of the pre-oral spines (18-19 vs 15-20 spines in the median group; 1 vs 1-2 pre-oral spines in each lateral group) and the presence of 10 transverse rows of spines on the body, three (incomplete) spine rows on the ventral sucker and large penetration gland-cells that do not cover ends of the caeca (Additional file 6: Table S3). However, the present cercaria possesses yellow pigment in the body, a ventral sucker slightly wider than the anterior organ, nine (vs 6-7) rows of post-oral spines and a different pattern of spines in the transverse rows of spines on the body [rows 1-2 double ventrally only ( $v s$ row 1); rows 9-10 with ventral interruption (vs rows 510 with both ventral and dorsal interruption); row 3 with additional spines laterally ( $v s$ anteriormost rows)]. Further differences include the lower ranges of the number of spines on the ventral sucker (103-119 vs 116-141), the presence of spines on the tail stem and furcae ( $v s$ absent) and the much smaller angle of bending of the tail stem in resting position $\left(<45^{\circ}\right.$ vs $\left.90^{\circ}\right)$ (Additional file 6: Table S3). Comparisons of the morphometric data revealed 
that both live and formalin-fixed isolates of D. spathaceum studied by us exhibit shorter and wider bodies (means $172 \times 51$ and $170 \times 53 \mu \mathrm{m}$, respectively, $v s 189 \times 46 \mu \mathrm{m})$, longer ventral suckers (means 30 and $31 \mu \mathrm{m}$, respectively, vs $25 \mu \mathrm{m}$ ), longer (means 219 and $250 \mu \mathrm{m}$, respectively, $v$ s $211 \mu \mathrm{m}$ ) but narrower tail stems (means 31 and $32 \mu \mathrm{m}$, respectively, $v s 37 \mu \mathrm{m}$ ), much longer furcae (means 260 and $252 \mu \mathrm{m}$, respectively, $v s 208 \mu \mathrm{m}$ ) and lower BL/TSL ratios (means 0.8 and 0.7 , respectively, vs 0.9) (Table 6). The above comparisons indicate that the morphology of the cercaria of $D$. spathaceum characterised molecularly in the present study departs from the single limited descriptions of cercariae of both $D$. spathaceum sensu Niewiadomska [27] and D. paracaudum sensu Niewiadomska [28]. It is unfortunate that the morphologies described by Niewidomska have not been confirmed for nearly 30 years.

Georgieva et al. [6] denoted as 'Clade Q' (questionable) a single genotype representing two cercarial isolates ex R. ovata identified as D. spathaceum (AF419275; AF419276) and two for a cercarial isolate ex $R$. ovata identified as D. parviventosum (AF419277; AF419278) by Niewiadomska \& Laskowski [23]; one metacercarial isolate ex $R$. rutilus submitted to GenBank as D. cf. parviventosum/spathaceum (JF775727) by Rellstab et al. [29]; and one cercarial isolate ex R. auricularia (JQ665458; isolate RA97) annotated as D. mergi in GenBank but published as D. spathaceum by Behrmann-Godel [17]. One additional metacercarial isolate belonging to 'Clade Q' has been recently sequenced and described by Pérez-delOlmo et al. [9]. Georgieva et al. [6] also suggested to use temporarily the name $D$. parviventosum as a label for the four identical sequences (AF419275-AF419278) of Niewiadomska \& Laskowski [23]. One of the important results of our integrative taxonomic approach is the clarification of the distinct status of $D$. parviventosum and its close relationship with the species/lineages of the 'D. mergi' species complex (see above). However, the species identification of the sequences within 'Clade Q' sensu Georgieva et al. [6] is still questionable. The fact that new isolates are being added to this clade ([9, 17]; present study) indicates that this lineage has a wider distribution and still requires taxonomic scrutiny. It is worth noting that the metacercaria of 'Diplostomum sp. Clade Q' ex Cyprinus carpio L. from the Ebro Delta in Spain described and sequenced by Pérez-del-Olmo et al. [9] was shown to possess a smaller oral sucker and a shorter holdfast organ compared with the Spanish and Polish (see Niewiadomska [27]) isolates of D. spathaceum plus a distinctly lower number of excretory granules in the secondary excretory system than the metacercariae of $D$. spathaceum sensu Niewiadomska [27]. The cercaria of the single isolate of 'Diplostomum sp. Clade Q' sequenced and described here keys down to $D$. spathaceum in the key by
Niewiadomska \& Kiselienè [10] and agrees with their description in many aspects. However, the present cercaria differs in having fewer pre-oral spines in the median group (9 vs 8-16), 12 post-oral rows of spines (vs 10-14), 10 pairs of caudal bodies (vs 11-12 pairs), as well as in the presence of two non-converging fields of dispersed spines in the hindbody ( $v s$ two fields converging ventrally) and of bands of scale-like spines on the tail stem and furcae ( $v s$ spines absent); spines on the latter enveloped by tegumental membrane forming a specific fish-fin like fin-fold (Additional file 6: Table S3). Although the metrical data for our isolate (live cercariae measured only) are not directly comparable with those by Niewiadomska [27] the former exhibits much lower values for the length of body (mean 224 vs $235 \mu \mathrm{m}$ ) and the ratios VSW/AOW (mean 1.3 vs 1.7) and BL/TSL (mean 0.8 vs 0.9 ) and much greater values for body width (mean $96 v s 73 \mu \mathrm{m}$ ) and for the size of the anterior organ (mean $80 \times 47 v s 68 \times 34 \mu \mathrm{m})$ and ventral sucker (mean $56 \times 65$ vs $53 \times 59 \mu \mathrm{m}$ ). The above comparisons indicate that the cercariae and metacercariae of 'Diplostomum sp. Clade Q' possess distinctive morphological characteristics that do not allow their identification as D. spathaceum sensu Niewiadomska [27]. The solution for the taxonomic status of this clade should await morphological and molecular data for the adult stages.

\section{Conclusion}

The integration of molecular and morphological evidence for Diplostomum spp. achieved in this study will serve as a baseline for species identification of these important parasites of snail and fish populations and thus advance further studies on the distribution of Diplostomum spp. in Europe.

\section{Additional files}

Additional file 1: Figure S1. Schematic illustration of a cercaria of Diplostomum spp. showing the metrical features used. Abbreviations: BL, body length; BW, maximum body width; $A O L$, anterior organ length; AOW, anterior organ maximum width; VSL, ventral sucker length; VSW, ventral sucker width; TSL, tail stem length; TSW, tail stem width (at base); $\mathrm{FL}$, furca length.

Additional file 2: Table S1. Summary data for $\operatorname{cox} 1$ sequences for Diplostomum spp. retrieved from GenBank.

Additional file 3: Figure S2. Cercariae of Diplostomum spp. Pre- and post-oral spines (light microscopy). A, Diplostomum parviventosum; B, Diplostomum mergi Lineage 4; C, 'Diplostomum mergi Lineage 2'; D, 'Diplostomum mergi Lineage 3'; E, F, Diplostomum pseudospathaceum (arrows indicate lateral spines); G. Diplostomum spathaceum.

Additional file 4: Figure S3. Cercariae of Diplostomum spp. Ventral sucker (light microscopy). A, Diplostomum parviventosum; B, Diplostomum mergi Lineage 4; C, 'Diplostomum mergi Lineage 2'; D, 'Diplostomum mergi Lineage 3'; E, 'Diplostomum sp. Clade Q'; F, Diplostomum pseudospathaceum; G. Diplostomum spathaceum.

Additional file 5: Figure S4. Cercariae of Diplostomum spp. Tail furcae (light microscopy). A, Diplostomum parviventosum; B, Diplostomum mergi Lineage 4; C, 'Diplostomum mergi Lineage 2'; D, 'Diplostomum mergi 
Lineage 3'; E, 'Diplostomum sp. Clade Q'; F, Diplostomum pseudospathaceum; G. Diplostomum spathaceum.

Additional file 6: Table S2. Comparative qualitative and meristic data for cercariae of the Diplostomum 'mergi' species complex. Table S3 Comparative qualitative and meristic data for cercariae of Diplostomum spathaceum, D. pseudospathaceum, D. paracaudum and 'Diplostomum sp. Clade Q' of Georgieva et al. [6].

\section{Competing interests}

The authors declare that they have no competing interests.

\section{Authors' contributions}

CS and MS: obtained samples, undertook the identification and morphological characterisation of the isolates and prepared the first draft of the manuscript. CS and SG: carried out the sequencing. SG: performed the phylogenetic analyses and drafted the correponding parts of the MS. BS and AK: conceived the study, discussed the results and helped draft the manuscript. All authors read and approved the final manuscript.

\section{Acknowledgements}

We thank Jana Köchling, Verena Altmann, Jessica Schwelm (University of Duisburg-Essen) for their assistance in sampling, Blanka Škoríková (Institute of Parasitology) for her kind help with figure preparations and Jiř́ Vaneček, Martina Tesařová and Petra Masařová (Laboratory of Electron Microscopy, Biology Centre, Czech Academy of Sciences) for their expert help in the SEM study. We thank two anonymous reviewers for their constructive comments which helped improve the manuscript. This study was partially funded by the Czech Science Foundation (15-14198S) and the 'Sichere Ruhr' project as part of the Bundesministerium für Bildung und Forschung (BMBF) program 'Sustainable Water Management' (grant 02WRS1283). CS benefited from a Deutsche Bundesstiftung Umwelt (DBU) PhD fellowship and a research grant by the Faculty of Biology of the University of Duisburg-Essen.

\section{Author details}

'Department of Aquatic Ecology and Centre for Water and Environmental Research (ZWU), University of Duisburg-Essen, Universitätsstraße 5, D-45141 Essen, Germany. ${ }^{2}$ Institute of Parasitology, Biology Centre of the Czech Academy of Sciences, Branišovská 31, 37005 České Budějovice, Czech Republic. ${ }^{3}$ Department of Zoology, University of Johannesburg, Auckland Park 2006, PO Box 524, Johannesburg, South Africa.

Received: 11 March 2015 Accepted: 18 May 2015

Published online: 03 June 2015

\section{References}

1. Criscione CD, Poulin R, Blouin MS. Molecular ecology of parasites: elucidating ecological and microevolutionary processes. Mol Ecol. 2005;14:2247-57.

2. Pérez-Ponce de León G, Nadler SA. What we don't recognize can hurt us: a plea for awareness about cryptic species. J Parasitol. 2010;96:453-64.

3. Lafferty K. Environmental parasitology: What can parasites tell us about human impacts on the environment? Parasitol Today. 1997;13:251-5.

4. Poulin R. Parasite biodiversity revisited: frontiers and constraints. Int Parasitol. 2014;44:581-9.

5. Locke SA, McLaughlin JD, Dayanandan S, Marcogliese DJ. Diversity, specificity and evidence of hybridization in Diplostomum spp. metacercariae in freshwater fishes is revealed by DNA barcodes and ITS sequences. Int J Parasitol. 2010;40:333-43

6. Georgieva S, Soldánová M, Pérez-del-Olmo A, Dangel RD, Sitko J, Sures B, et al. Molecular prospecting for European Diplostomum (Digenea: Diplostomidae) reveals cryptic diversity. Int J Parasitol. 2013:43:57-72.

7. Blasco-Costa I, Faltýnková A, Georgieva S, Skírnisson K, Scholz T, Kostadinova A. Fish pathogens near the Arctic Circle: molecular, morphological and ecological evidence for unexpected diversity of Diplostomum (Digenea: Diplostomidae) in Iceland. Int J Parasitol. 2014;44:703-15.

8. Faltýnková A, Georgieva S, Kostadinova A, Blasco-Costa I, Scholz T, Skírnisson K. Diplostomum von Nordmann, 1832 (Digenea: Diplostomidae) in the sub-Arctic: descriptions of the larval stages of six species discovered recently in Iceland. Sys Parasitol. 2014;89:195-213.

9. Pérez-del-Olmo A, Georgieva S, Pula HJ, Kostadinova A. Molecular and morphological evidence for three species of Diplostomum (Digenea:
Diplostomidae), parasites of fishes and fish-eating birds in Spain. Parasite Vector. 2014:7:502.

10. Niewiadomska K, Kiselienè V. Diplostomum cercariae (Digenea) in snails from Lithuania. II Survey of species Acta Zool Lituan. 1994:39:179-86.

11. Abramoff MD, Magalhaes PJ, Ram SJ. Image processing with Image. J Biophotonics Internat. 2004;11:36-42.

12. Georgieva S, Selbach C, Faltýnková A, Soldánová M, Sures B, Skírnisson K, et al. New cryptic species of the 'revolutum' group of Echinostoma (Digenea: Echinostomatidae) revealed by molecular and morphological data. Parasite Vector. 2013;6:64

13. Moszczynska A, Locke SA, McLaughlin JD, Marcogliese DJ, Crease TJ. Development of primers for the mitochondrial cytochrome $\mathrm{c}$ oxidase I gene in digenetic trematodes illustrates the challenge of barcoding parasitic helminths. Mol Ecol Resour. 2009;9:75-82.

14. Galazzo DE, Dayanandan S, Marcogliese DJ, McLaughlin JD. Molecular systematics of some North American species of Diplostomum (Digenea) based on rDNA-sequence data and comparisons with European congeners. Can J Zool. 2002;80:2207-17.

15. Tamura K, Stecher G, Peterson D, Filipski A, Kumar S. MEGA6: Molecular evolutionary genetics analysis version 6.0. Mol Biol Evol. 2013;30:2725-9.

16. Telford MJ, Herniou EA, Russell RB, Littlewood DTJ. Changes in mitochondrial genetic codes as phylogenetic characters: Two examples from the flatworms. Proc Natl Acad Sci U S A. 2000;97:11359-64.

17. Behrmann-Godel J. Parasite identification, succession and infection pathways in perch fry (Perca fluviatilis): new insights through a combined morphological and genetic approach. Parasitology. 2013;140:509-20

18. Haarder S, Jørgensen K, Kania PW, Skovgaard A, Buchmann K. Occurrence of Diplostomum pseudospathaceum Niewiadomska, 1984 and D. mergi Dubois, 1932 (Digenea: Diplostomidae) in Danish freshwater snails: ecological and molecular data. Folia Parasitol. 2013;60:177-80

19. Guindon S, Gascuel O. A simple, fast and accurate algorithm to estimate large phylogenies by maximum-likelihood. Syst Biol. 2003;52:696-704.

20. Darriba D, Taboada GL, Doallo R, Posada D. jModelTest 2: more models, new heuristics and parallel computing. Nat Methods. 2012;9:772.

21. Ronquist F, Teslenko M, van der Mark P, Ayres DL, Darling A, Hohna S, et al. MrBayes 3.2: efficient Bayesian phylogenetic inference and model choice across a large model space. Syst Biol. 2012:61:539-42.

22. Huelsenbeck JP, Ronquist F, Nielsen R, Bollback JP. Bayesian Inference of phylogeny and its impact on evolutionary biology. Science. 2001;294:2310-4.

23. Niewiadomska K, Laskowski Z. Systematic relationships among six species of Diplostomum Nordmann, 1832 (Digenea) based on morphological and molecular data. Acta Parasitol. 2002;47:20-8.

24. Stenko RP. [On studying fauna of trematoda larvae of fresh-water Crimean mollusks.]. Vestn Zool. 1976;5:42-6. In Russian.

25. Faltýnková A. Larval trematodes (Digenea) in molluscs from small water bodies near České Budějovice, Czech Republic. Acta Parasitol. 2005;50:49-55.

26. Soldánová M, Selbach C, Sures B, Kostadinova A, Pérez-del-Olmo A. Larval trematode communities in Radix auricularia and Lymnaea stagnalis in a reservoir system of the Ruhr River. Parasite Vector. 2010;3:56.

27. Niewiadomska K. Verification of the life-cycles of Diplostomum spathaceum (Rudolphi, 1819) and D. pseudospathaceum Niewiadomska, 1984 (Trematoda, Diplostomidae). Syst Parasitol. 1986;8:23-31.

28. Niewiadomska K. Diplostomum paracaudum (lles, 1959) Shigin, 1977 (Digenea, Diplostomidae) and its larval stages - a new record from Poland Acta Parasitol Polon. 1987:31:199-210.

29. Rellstab C, Louhi K-R, Karvonen A, Jokela J. Analysis of trematode parasite communities in fish eye lenses by pyrosequencing of naturally pooled DNA. Infect Genet Evol. 2011;11:1276-86. 